\title{
International effects of euro area forward guidance
}

\section{CAMA Working Paper 54/2020 May 2020}

Maximilian Bock

Vienna University of Business and Economics

Martin Feldkircher

Oesterreichische Nationalbank

\section{Pierre L. Siklos}

Wilfrid Laurier University, Balsillie School of International Affairs

Centre for Applied Macroeconomic Analysis, ANU

\section{Abstract}

This paper explores the domestic and international effects of an increase in observed interest rates (conventional monetary policy) and expected interest rates (forward guidance). We find significant spillovers to a broad range of countries when both are subject to a tightening shock: Output growth and inflation decelerate and equity returns decline. Currencies of euro area neighboring countries tend to depreciate against the euro. A tightening forward guidance shock triggers more persistent effects on euro area and international interest rates. We find that international effects vary over the sample period when either interest rates are shocked. 


\title{
Keywords
}

Spillovers, interest rate expectations, forward guidance, GVAR

\author{
JEL Classification
}

$\mathrm{E} 5, \mathrm{~F} 3, \mathrm{C} 11, \mathrm{C} 30$

Address for correspondence:

(E) cama.admin@anu.edu.au

ISSN 2206-0332

The Centre for Applied Macroeconomic Analysis in the Crawford School of Public Policy has been established to build strong links between professional macroeconomists. It provides a forum for quality macroeconomic research and discussion of policy issues between academia, government and the private sector.

The Crawford School of Public Policy is the Australian National University's public policy school, serving and influencing Australia, Asia and the Pacific through advanced policy research, graduate and executive education, and policy impact. 


\title{
International effects of euro area forward guidance
}

\author{
MAXIMILIAN BÖCK ${ }^{1}$ AND MARTIN FELDKIRCHER ${ }^{2}$ AND PIERRE L. \\ SIKLOS $^{3 *}$ \\ ${ }^{1}$ Vienna University of Business and Economics (WU Wien) \\ ${ }^{2}$ Oesterreichische Nationalbank (OeNB) \\ ${ }^{3}$ Wilfrid Laurier University, Balsillie School of International Affairs and Centre for \\ Applied Macroeconomic Analysis (CAMA)
}

\begin{abstract}
This paper explores the domestic and international effects of an increase in observed interest rates (conventional monetary policy) and expected interest rates (forward guidance). We find significant spillovers to a broad range of countries when both are subject to a tightening shock: Output growth and inflation decelerate and equity returns decline. Currencies of euro area neighboring countries tend to depreciate against the euro. A tightening forward guidance shock triggers more persistent effects on euro area and international interest rates. We find that international effects vary over the sample period when either interest rates are shocked.
\end{abstract}

JEL CODES: E5, F3, C11, C30

KEYWORDS: Spillovers, interest rate expectations, forward guidance, GVAR

May 12, 2020

\footnotetext{
${ }^{*}$ Corresponding author: Martin Feldkircher. Oesterreichische Nationalbank (OeNB). Address: Otto-Wagner-Platz 3, 1090 Wien, Austria. Email: martin.feldkircher@oenb.at. We thank André Geis, Martin Geiger, Florian Huber, Tomi Kortela, Zsolt Kuti, Martin Mandler as well as participants of the 22nd Central Bank Macroeconomic Modelling workshop, Dilijan, participants of the recent trends in central bank macroeconomic modelling workshop of the Central Bank of Russia, Tula participants of an internal seminar at the European Commission, participants of the 17th ESCB Emerging Markets Workshop, Vienna, and participants of the annual conference of the Austrian economic association, Vienna, for helpful comments.
} 


\section{INTRODUCTION: MOTIVATION AND BACKGROUND}

Best practice in the conduct of monetary policy requires that the central bank be forwardlooking. Ordinarily, this means providing markets and the public with information about the economic outlook. Even if, as Michael Woodford points out in his seminal book, Interest and Prices (Woodford, 2003), the outlook contains an element of history dependence, transparency puts pressure on the central bank to guide markets about the likely future path of interest rates. Providing clues about the future stance of monetary policy has been termed forward guidance (FG). Nevertheless, forward guidance comes in several forms depending on how it is presented and the degree of commitment on the part of the central bank to follow through on its views about the future. A major difficulty with the current analytical framework is the presumption of perfect central bank credibility. Yet, there is growing evidence not only that central banks are, at times, not credible but also that credibility changes over time (e.g., see Bordo and Siklos, 2018; 2019). At the empirical level, there is no effective recognition of changing central bank credibility nor is there explicit recognition that central banks communicate via words and not only by providing, for example, potential future interest rate paths.

Given intense interest about the effectiveness of FG in recent years it is understandable that the literature has already generated reviews of the policy to date. Filardo and Hofmann (2014) is a recent survey. The authors conclude that while there have been some successes, they do not recommend the policy unreservedly because the impact of FG on interest rate expectations is unclear. Ehrmann et al. (2019) find that FG can increase uncertainty. Other attempts to investigate the impact of forward guidance have also been generated. Additionally, one might add that sample sensitivity is another less emphasized reason for the mixed findings reported in the extant literature. Put another way, this factor may well be a reflection of changing central bank credibility over time.

There have been many attempts to disentangle how expectations about future policy are influenced by various real and financial shocks that hit an economy, in addition to any central bank announcements whether domestically sourced or originating from external influences. Not surprisingly, the evidence is mixed with disagreement especially about whether any loosening bias, for example, effectively translates into the central bank expecting bad economic news in future as it attempts to forestall this state by promising, if necessary, to ease future monetary policy. The current absence of consensus about the effectiveness of FG can be explained by several factors. In this connection, a distinction between Odyssean and Delphic forms of FG has been proposed as a way of clarifying the key positions in the ongoing debate. ${ }^{1}$

A challenge that plagues the literature is the inherent endogeneity that arises because current policy decisions are based on a mix of history dependent factors, as well as forecasts of future economic conditions. Hence, identification is necessary to disentangle in observed data promises to act in future from the central bank usage of the outlook to set the current stance of monetary policy. This is the inevitable consequence of a monetary policy that is forward-looking, as best practice requires. As a result, a plethora of identifying restrictions have been proposed to enable researchers to make inferences about the respective roles of past performance versus policy makers' outlook and how they intend to

${ }^{1}$ Delphic forward guidance is determined by the central bank's own interest rate projections; Odyssean guidance represents a commitment to a particular future interest rate path. As noted below, it is often forgotten that the commitment is either explicitly and almost certainly conditional on how future economic data evolve. 
respond to them. One strand of the literature uses high frequency identification which boils down to collecting data on financial variables (e.g., interest rates at different maturities, exchange rates, equity prices, etc.) shortly before and after a policy announcement. Using a short time window is one strategy of preventing other news events from contaminating the source of any changes in, say, market interest rates and the wider public response to potential modifications in the policy stance. Depending on the scope of the analysis, these changes are then explained in a second step using factor analysis to reflect information about current rates (conventional monetary policy, target factor) and future rates (forward guidance, path factor). These factors then serve as external instruments and the effect of monetary policy on focal variables can be assessed using either linear regressions (Campbell et al., 2012; Gürkaynak et al., 2015) or vector autoregressions (Altavilla et al., 2019; Bundick and Smith, 0; Jarociński and Karadi, 2019; Nakamura and Steinsson, 2018).

A drawback of high frequency identification is that it can reveal effects that are not consistent with standard economic theory. For example, Miranda-Agrippino and Ricco (2015) show that monetary policy shocks identified with high frequency data often lead to output and / or price puzzles. Campbell et al. (2012) find that a FG tightening lowers the unemployment rate and increases inflation for the US economy. Bundick and Smith (0) finds the opposite, namely a gradual decline in economic activity accompanied by a decrease in investment and capital utilization and modest disinflation.

A second strand of the literature combines high frequency identification with data on expectations. Surveys of professional forecasters are often used and relate to expectations on output, inflation and interest rates. Andrade and Ferroni (2018) disentangle Delphic from Odyssean FG shocks by assuming that the former is accompanied by an upward movement in inflation expectations whereas the opposite is the case for the forward guidance shock of the Odyssean type. This assumption is based on a smallscale theoretical model and empirically corroborated by de la Barrera et al. (2017) using an event study approach. Andrade and Ferroni (2018) find that an (Odyssean) FG tightening has significant negative effects on output and prices in the euro area. Callum et al. (2018) set up a two-country DSGE model to capture the transmission of forward guidance shocks from the USA to Canada. Their work emphasizes the importance of time variation in FG spillovers: While in general effects of FG on Canadian output are twice as large as those from conventional monetary policy, they decrease significantly if demand in the US economy is weak.

D'Amico and King (2015) identify interest rate expectation shocks for the US economy using a novel combination of zero and sign restrictions (Arias et al., 2018). They find that a decrease in expected interest rates triggers large, immediate, and persistent upward effects on inflation and real activity. These effects tend to rise with the expectations horizon.

In this paper we investigate the domestic and international effects of rate FG by looking at changes in interest rate expectations, while actual rates do not move. Similar to D'Amico and King (2015) we assume "rationality" conditions to ensure that responses of actual data and expectations data do not diverge by the end of the forecasting horizon. Therefore, forecasts can deviate from observed values in the short-run, which implies that we do not assume full credibility of the central bank at all times. The results of this FG shock are compared to effects of a conventional monetary policy shock. We address potential time-variation of the effects by estimating a global time-varying parameter vector autoregressive model, advocated in Crespo Cuaresma et al. (2019). Our results show that both effects generate significant spillovers to economic activity and inflation as well as global equity returns. While the conventional 
monetary policy shock is more precisely estimated during the period of the global financial crisis and effects abate thereafter, the rate FG shock shows also pronounced and precisely estimated effects during the subsequent period of the zero lower bound. The bottom line is that, regardless of its form, FG remains a potentially powerful tool, especially in a financial crisis. Our results also suggest that the emphasis on how FG shocks affect the rest of the world omits the potential global effects of FG shocks from the euro area.

The paper is structured as follows: The next section introduces the data and section 3 the Bayesian GVAR model with time-varing parameters and stochastic volatility (TTVP-SV-GVAR). Section 4 describes the empirical results and section 5 concludes.

\section{DATA AND SOME STYLIZED FACTS}

We use monthly data spanning the period from $2001 \mathrm{~m} 01$ to $2018 \mathrm{~m} 06$. For most economies, we have collected data on short-term interest rates (3-months money market rates, $i_{i t}^{s}$ ), consumer price inflation $\left(D p_{i t}\right.$, year-on-year growth rate of index $\left.2010=100\right)$, long-term interest rates $\left(i_{i t}^{l}\right.$, 10-year government bond yields), monthly stock market returns $\left(e q_{i t}\right)$, and the nominal exchange rate vis-à-vis the euro $\left(e r_{i t}\right)$. For the latter an increase implies a depreciation of the local currency against the euro. As a measure of economic activity, we use real GDP growth ( $y_{i t}$, in year-on-year terms), disaggregated to the monthly frequency by using the Chow-Lin method (Chow and Lin, 1971) and industrial production as a high frequency indicator. This yields somewhat less volatile growth rates than using industrial production as economic activity index itself. Data on industrial production and consumer prices are de-seasonalized.

These data are collected for a broad set of countries, namely the euro area (EA), countries from Central, Eastern and Southeastern Europe (CESEE, Bulgaria, Croatia, the Czech Republic, Hungary, Poland, Romania, Russia and Turkey) and other advanced European countries (Europe, Denmark, Great Britain, Norway, Sweden and Switzerland). We include Russia and Turkey due to their close economic ties with the euro area as well as the USA, China, Canada and Japan (Other advanced) to control for global factors. That leaves us with a sample of good coverage of European and G-8 industrialized advanced economies. The countries in our sample account for about $70 \%$ of global nominal output (averaged over the years 2010 to 2016) and reflect the most important trading partners of the euro area.

For a typical non-euro area country $i$, this yields a $k_{i} \times 1$ vector of endogenous variables, $\boldsymbol{x}_{i t}$ :

$$
\boldsymbol{x}_{i t}=\left(y_{i t}, D p_{i t}, i_{i t}^{s}, i_{i t}^{l}, e q_{i t}, e r_{i t}\right)^{\prime}
$$

The euro area model differs from the remaining countries in terms of variable coverage. To identify the forward guidance shock, we have to include data on expectations. More specifically, we include one-year ahead forecasts of real GDP growth $\left(y_{i t}^{t+12}\right)$, inflation $\left(D p_{i t}^{t+12}\right)$ and short-term interest rates

$\left(i_{i t}^{s, t+12}\right)$. The data stem from Consensus economics and are transformed to a fixed-horizon forecast as in Siklos (2013). As a control variable, we also include the Swiss Economic Institute's (KOF) Monetary Policy Communicator index $\left(m p c_{i t}^{c o m m}\right)$. The indicator reflects risks to price stability and is constructed by aggregating statements made by the ECB president about future price stability at monthly 
press conferences. ${ }^{2}$ It is also shown that it leads the policy rate by two to three months and has - by construction - a strong positive relationship with inflation expectations (Neuenkirch, 2013). We include the indicator to first control for short-term interest rate expectations and secondly for Delphic forward guidance - the latter which typically shows a strong positive correlation of interest rate expectations and inflation expectations (Andrade and Ferroni, 2018; de la Barrera et al., 2017). Finally, we also include three Nelson-Siegel factors that reflect, level $\left(\beta_{i t}^{0}\right)$, slope $\left(\beta_{i t}^{1}\right)$ and curvature $\left(\beta_{i t}^{2}\right)$ of the joint euro area yield curve (Nelson and Siegel, 1987; Diebold and Li, 2006; Diebold et al., 2006). The factors have been estimated using a dynamic, arbitrage free Nelson-Siegel model and daily data on overnight indexed swaps (OIS). ${ }^{3}$

Note that in accordance with the literature, the slope factor is inversely defined, i.e., $\beta_{i t}^{2}$ approximates the difference between short- and long-term rates (Diebold and Li, 2006). We include the yield curve factors to further distinguish the conventional monetary policy from the FG shocks - the latter should mainly work on the middle segment of the yield curve (Brand et al., 2010; Altavilla et al., 2019) and hence affect the curvature factor. ${ }^{4}$

The euro area country model $i=0$ then features the following variables:

$$
\boldsymbol{x}_{0 t}=\left(y_{0 t}, D p_{0 t}, i_{0 t}^{s}, y_{0 t}^{t+12}, D p_{0 t}^{t+12}, i_{0 t}^{s, t+12}, e q_{0 t}, m p c_{0 t}^{c o m m}, \beta_{0 t}^{0}, \beta_{0 t}^{1}, \beta_{0 t}^{2}\right)^{\prime} .
$$

Figure 1 shows the variables related to monetary policy.

We see that inflation pressure, measured by the KOF indicator, evolves in cycles, i.e., there are consecutive press conferences that either suggest positive or negative pressure on inflation. This is not surprising, since the monetary policy stance and the economic conditions do not change abruptly. Over the latest sub-period of the sample, values for the KOF indicator are positive. This can be seen as a sign that the ECB expects the unconventional monetary policy measures undertaken over this sub-period to be successful in driving up inflation. On the right-hand side of the figure, we plot expectations of real GDP growth, inflation and short-term interest rates, transformed to fixed-event, one-year ahead forecasts. Also here we see positive expectations of economic activity and inflation over the most recent sample period.

In Fig. 2 we show simple correlations of the monetary policy an expectations variables over the preand post-crisis period.

The plot shows that interest rates, actual and expectations and the shadow rate, all were closely related to each other and positively correlated in the pre-crisis period. The KOF communicator index is also positively correlated with the remaining variables (most strongly so with expected inflation), but seems to stand apart seen from its isolation from the other variables in the figures. If we now look at the post-crisis period we see that correlations change, also drastically so from positive to negative. More specifically, both the KOF communicator index and real GDP growth expectations are now negatively related with measures of interest rates. Also, the association between inflation expectations and the monetary policy

\footnotetext{
2The indicator and further explanations are available at https://www.kof.ethz.ch/en/forecasts-and-indicators/ indicators/kof-monetary-policy-communicator.html.

${ }^{3}$ We thank Tomi Kortela for sharing his estimates with us. Prior to 2006 and due to lack of availability, OIS rates are approximated by the mean of German and French government bond yields. For more details, see Kortela and Nelimarkka (2020) and Altavilla et al. (2019) for a similar approximation of euro area yields.

${ }^{4}$ Conversely, Hubert and Labondance (2018), using an event study approach, find that forward guidance has a significant effect on the whole term structure of interest rates - also on longer tenors.
} 
Fig. 1: Euro area monetary policy variables - data overview

(a) $m p c^{c o m m} / i^{s}$

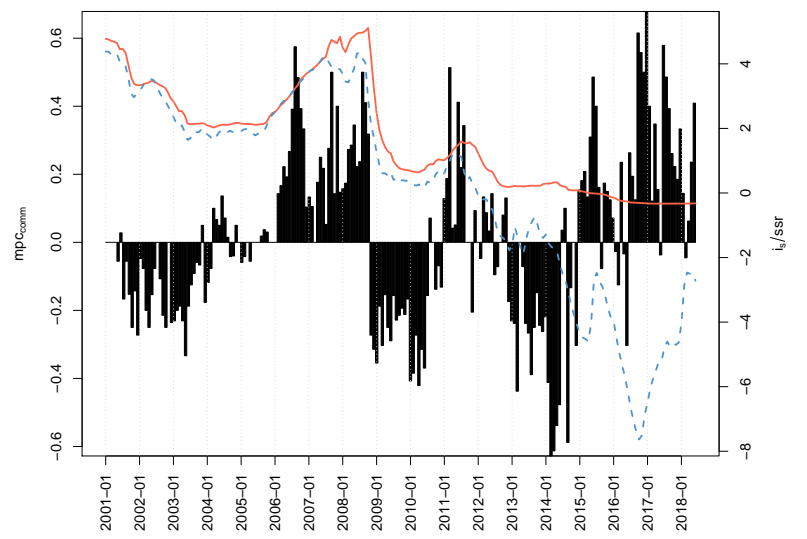

(b) Expectations

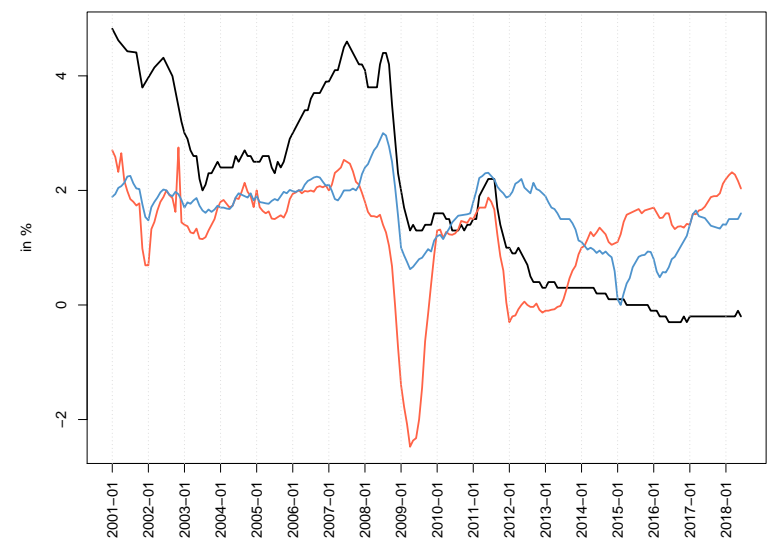

Notes: The figure on the left-hand side shows the KOF MPC communicator ( $m p c^{c o m m}$, black solid line) index on the left-hand scale, and the euro area short term interest rates $\left(i^{s}\right.$, red solid line) and the shadow rate of Krippner (ssr, blue dotted line Krippner, 2013) on the right-hand scale. The right-hand side figure shows one-year head survey expectations of real GDP growth (red, $\left.y^{t+12}\right)$, inflation $\left(D p^{t+12}\right.$, blue) and short-term interest rates $\left(i^{s, t+12}\right.$, black $)$

Fig. 2: Sub-sample correlation of euro area monetary policy and survey expectations variables

(a) $2001 \mathrm{~m} 1-2008 \mathrm{~m} 12$

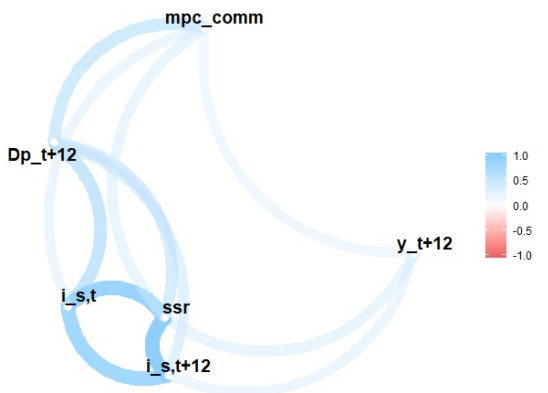

(b) $2009 \mathrm{~m} 1-2018 \mathrm{~m} 6$

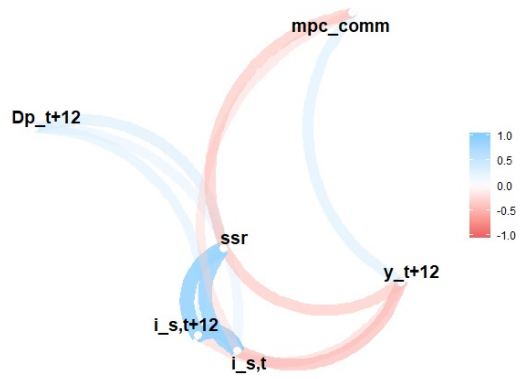

Notes: The figure shows simple correlation over two sub-periods. Positive correlations in blue, negative correlations in red.

variables differs across the two sub-periods. Frequent changes of the macroeconomic effects of FG have also been reported in Andrade and Ferroni (2018). Accordingly, we opt for a time-varying parameter framework to properly assess the effects of FG in the euro area. 


\section{ECONOMETRIC FRAMEWORK}

To assess spillovers of the euro area shocks, and to account for potential changes in these effects over time, we estimate a global vector autoregressive model with time-varying parameters and stochastic volatility (TVP-SV-GVAR model), recently proposed in Crespo Cuaresma et al. (2019)

In general, the structure of a GVAR model implies two distinct stages in the estimation process. In the first stage, $N+1$ country-specific multivariate time series models are specified, each of them including weakly exogenous regressors that aim to capture cross-country linkages. It is in this stage that we introduce time variation by using the mixture innovation specification of Huber et al. (2019). In the second stage, these models are combined using country weights to form a global model which then forms the basis for the impulse response analysis.

\subsection{A dynamic global macroeconomic model}

Let the endogenous variables for country $i=0, \ldots, N$ be contained in a $k_{i} \times 1$ vector $\boldsymbol{x}_{i t}=\left(x_{i 1, t}, \ldots, x_{i k_{i}, t}\right)^{\prime}$. In addition, all country-specific models feature a set of $k_{i}^{*}$ weakly exogenous regressors $x_{i t}^{*}=\left(x_{i 1, t}^{*}, \ldots, x_{i k_{i}, t}^{*}\right)^{\prime}$ constructed as weighted averages of the endogenous variables in other economies,

$$
x_{i j, t}^{*}=\sum_{c=0}^{N} w_{i c} x_{c j, t} \text { for } j=1, \ldots, k_{i}^{*},
$$

where $w_{i c}$ is the weight corresponding to the $j$ th variable of country $c$ in country $i$ 's specification. These weights are assumed to be related to bilateral trade exposure ${ }^{5}$, sum up to unity and only off-diagonal elements are non-zero $\left(\sum_{c=0}^{N} w_{i c}=1\right.$ and $\left.w_{i i}=0\right)$. In line with the bulk of the literature on GVAR modeling, we assume that all variables and countries are linked by the same set of weights which is fixed over time (Dees et al., 2007). We follow Crespo Cuaresma et al. (2019) and specify country-specific structural VARX*(1,1) models with time-varying parameters and stochastic volatility:

$$
\boldsymbol{Q}_{i 0, t} \boldsymbol{x}_{i t}=\boldsymbol{A}_{i 1, t} \boldsymbol{x}_{i t-1}+\boldsymbol{B}_{i 0, t} \boldsymbol{x}_{i t}^{*}+\boldsymbol{B}_{i 1, t} \boldsymbol{x}_{i t-1}^{*}+\boldsymbol{\varepsilon}_{i t} \quad \boldsymbol{\varepsilon}_{i t} \sim \mathcal{N}\left(0, \boldsymbol{D}_{i t}\right)
$$

with $\boldsymbol{Q}_{i 0, t}$ denoting a $k_{i} \times k_{i}$ matrix of structural coefficients $\boldsymbol{A}_{i 1, t}$ is a $k_{i} \times k_{i}$ matrix of coefficients associated with the lagged endogenous variables and $\boldsymbol{B}_{i q, t}(q=0, \ldots, 1)$ denote $k_{i} \times k_{i}^{*}$ dimensional coefficient matrices corresponding to the $k_{i}^{*}$ weakly exogenous variables in $\boldsymbol{x}_{i t}^{*}$. The matrix of structural coefficients, $\boldsymbol{Q}_{i 0, t}$, is a lower triangular matrix with a diagonal of ones and captures the contemporaneous relationships between the variables in $\boldsymbol{x}_{i t}$. Estimating the structural form of the model (i.e., with the errors being orthogonal) allows us to use equation-by-equation estimation which considerably speeds up computational time (for a recent similar approach, see Crespo Cuaresma et al., 2019; Huber et al., 2019; Koop et al., 2019). ${ }^{6}$ For the error term, we assume that $\boldsymbol{D}_{i t}=\operatorname{diag}\left(\lambda_{i 0, t}, \ldots, \lambda_{i k_{i}, t}\right)$. That is, while the

\footnotetext{
${ }^{5}$ More precisely, we use annual data from the World Input Output Database (WIOD), averaged over the period from from 2000 to 2014. The data were retrieved from http://www. wiod.org/home and only available up until 2014. For a detailed description see Timmer et al. (2015).

${ }^{6}$ Introducing the lower triangular matrix renders our estimation potentially dependent on the ordering of the variables. However, since we are ultimately interested in impulse responses identified using an order-invariant identification scheme - zero and sign restrictions - our results turn out not to be sensitive to the arrangement of the variables in the model.
} 
off-diagonal elements within the country model are zero (the relationships already captured by $\boldsymbol{Q}_{i 0, t}$ ), the variances of the residuals of the model are allowed to vary over time. These are assumed to follow a stationary autoregressive process,

$$
\log \left(\lambda_{i l, t}\right)=\mu_{i l}+\rho_{i l}\left(\log \left(\lambda_{i l, t-1}\right)-\mu_{i l}\right)+v_{i l, t}, v_{i l, t} \sim \mathcal{N}\left(0, \varsigma_{i l}^{2}\right)
$$

where $\mu_{i l}$ denotes the unconditional expectation of the log-volatility, $\rho_{i l}$ the corresponding persistence parameter and $\varsigma_{i l}^{2}$ is the innovation variance of the process. Allowing for stochastic volatility ensures that changes in the parameters reflect changes in the underlying macroeconomic relationships and are not confounded by a wrongly assumed constant error variance. Also, with reference to the following empirical application that features expectations data for the euro area, having a specification that allows for heteroskedasticity, seems essential (Galati et al., 2011; de la Barrera et al., 2017).

In the second stage of the GVAR framework, the coefficients of the single country models can be stacked to yield a global vector autoregressive model. For that purpose, we rewrite the $N+1$ country specific models in terms of a global vector $\boldsymbol{x}_{t}=\left(\boldsymbol{x}_{0 t}^{\prime}, \ldots, \boldsymbol{x}_{N t}^{\prime}\right)^{\prime}$ of dimension $k=\sum_{i=0}^{N} k_{i}$ (Pesaran et al., 2004). More specifically, we define country-specific link matrices $\boldsymbol{W}_{i}(i=1, \ldots, N)$ and selection matrices $S_{i}$, both of dimension $\left(k_{i}+k_{i}^{*}\right) \times k$. The selection matrix is composed of zero elements, with unit values only on the elements that singles out the variables for country $i$ from the global vector $\boldsymbol{x}_{t}$.

$$
\begin{aligned}
\boldsymbol{Q}_{i 0, t} \boldsymbol{S}_{i} \boldsymbol{x}_{t} & =\boldsymbol{A}_{i 1, t} \boldsymbol{S}_{i} \boldsymbol{x}_{t-1}+\boldsymbol{B}_{i 0, t} \boldsymbol{W}_{i} \boldsymbol{x}_{t}+\boldsymbol{B}_{i 1, t} \boldsymbol{W}_{i} \boldsymbol{x}_{t-1}+\boldsymbol{\varepsilon}_{i t} \\
\left(\boldsymbol{Q}_{i 0, t} \boldsymbol{S}_{i}-\boldsymbol{B}_{i 0, t} \boldsymbol{W}_{i}\right) \boldsymbol{x}_{t} & =\left(\boldsymbol{A}_{i 1, t} \boldsymbol{S}_{i}+\boldsymbol{B}_{i 1, t} \boldsymbol{W}_{i}\right) \boldsymbol{x}_{t-1}+\boldsymbol{\varepsilon}_{i t} \\
\boldsymbol{G}_{i, t} \boldsymbol{x}_{t} & =\boldsymbol{H}_{i t} \boldsymbol{x}_{t-1}+\boldsymbol{\varepsilon}_{i t}
\end{aligned}
$$

with $\boldsymbol{G}_{i, t}=\left(\boldsymbol{Q}_{i 0, t} \boldsymbol{S}_{i}-\boldsymbol{B}_{i 0, t} \boldsymbol{W}_{i}\right)$ and $\boldsymbol{H}_{i t}=\boldsymbol{A}_{i 1, t} \boldsymbol{S}_{i}+\boldsymbol{B}_{i 1, t} \boldsymbol{W}_{i}$. Stacking the equations $N+1$ times yields the global representation of the model

$$
\boldsymbol{G}_{t} \boldsymbol{x}_{t}=\boldsymbol{H}_{t} \boldsymbol{x}_{\boldsymbol{t}-\mathbf{1}}+\boldsymbol{\varepsilon}_{t}, \quad \boldsymbol{\varepsilon}_{t} \sim N\left(0, \boldsymbol{\Sigma}_{t}\right)
$$

Equation (6) resembles a large VAR model with drifting coefficients and stochastic volatility, which we are going to estimate using Bayesian techniques. Following Huber (2016), we assume a block-diagonal $\boldsymbol{\Sigma}_{t}$. This is a stricter version of the implicit assumption in the GVAR framework that cross-country reduced form residual correlation is weak, which can be indirectly tested by examining the pairwise cross-country correlation of the country models' residuals (see the appendix, Fig. B.1). Note, however, that blockdiagonality of $\boldsymbol{\Sigma}_{t}$ does not restrict immediate cross-country spillovers to be zero, since pre-multiplying Eq. (6) with $\boldsymbol{G}_{t}^{-1}$ establishes contemporaneous links as a function of the underlying weights.

\subsection{Modeling time variation in the regression coefficients}

To model and estimate time variation in the coefficients, we use the model of Huber et al. (2019) that has been recently applied in the GVAR context by Crespo Cuaresma et al. (2019). In a nutshell, this model estimate a latent threshold for each coefficient of the model. Small movements of the coefficients that not 
surpass the threshold (in absolute values) are deemed negligible and the corresponding coefficient held constant. This specification hence allows for a parsimonious way of modeling time-variation, which is necessary in order to obtain precise estimates and avoid overfitting.

Stacking the lagged endogenous and weakly exogenous variables in an $m_{i}$-dimensional vector, with $m_{i}=k_{i}+k_{i}^{*}(1+1)$,

$$
z_{i t}=\left(x_{i t-1}^{\prime}, x_{i t}^{*^{\prime}}, x_{i t-1}^{*^{\prime}}\right)^{\prime}
$$

and collecting all coefficients in a $m_{i} \times k_{i}$ matrix $\boldsymbol{\Psi}_{i t}=\left(\boldsymbol{A}_{i 1, t}, \boldsymbol{B}_{i 0, t}, \boldsymbol{B}_{i 1, t}\right)^{\prime}$ allows us to rewrite Eq. (4) as

$$
\boldsymbol{Q}_{i 0, t} \boldsymbol{x}_{i t}=\left(\boldsymbol{I}_{k_{i}} \otimes z_{i t}^{\prime}\right) \boldsymbol{\Psi}_{i t}+\varepsilon_{i t}
$$

We let $\psi_{i t}=\operatorname{vec}\left(\boldsymbol{\Psi}_{i t}\right)$ and collect the free elements elements of $\boldsymbol{Q}_{i 0, t}$ in a $l_{i}=k_{i}\left(k_{i}-1\right) / 2$-dimensional vector $\boldsymbol{a}_{i 0, t}$.

For each individual coefficient in $\boldsymbol{\xi}_{i}=\left(\boldsymbol{q}_{i 0, t}^{\prime}, \boldsymbol{\psi}_{i t}^{\prime}\right)^{\prime}$, we assume a random walk law of motion,

$$
\xi_{i j, t}=\xi_{i j, t-1}+\eta_{i j, t}, \text { for } j=1, \ldots, s_{i},
$$

with $s_{i}=l_{i}+k_{i}\left(m_{i} k_{i}\right)$ and $\eta_{i j, t}$ being a white noise shock with time-varying variance $\vartheta_{i j, t}$. Here we follow Huber et al. (2019) and assume that $\vartheta_{i j, t}$ evolves according to

$$
\vartheta_{i j, t}=\left(1-d_{i j, t}\right) \vartheta_{i j, 0}+d_{i j, t} \vartheta_{i j, 1}
$$

whereby $\vartheta_{i j, 1} \gg \vartheta_{i j, 0}$ and $\vartheta_{i j, 0}$ is set close to zero. Moreover, let $d_{i j, t}$ denote a binary random variable that follows an independent Bernoulli distribution with,

$$
d_{i j, t}=\left\{\begin{array}{lll}
1 & \text { with probability } & p_{i j} \\
0 & \text { with probability } \quad 1-p_{i j}
\end{array}\right.
$$

This specification captures the notion that if the period-on-period change in the respective parameter is large, the unconditional probability (i.e., with $\xi_{i j, t}$ integrated out) of $d_{i j, t}=1$ is also large. ${ }^{7}$ It also nests a wide variety of competing models. For instance, if $d_{i j, t}=1$ for all $t$ we obtain a standard time-varying parameter specification whereas in the case of $d_{i j, t}=0$ for all $t$, we end up having a nearly constant parameter specification (as the variance of $\eta_{i j, t}$ will be relatively small). Cases in between are also possible, implying that our framework accommodates situations where parameters might be time-varying during certain points in time and effectively constant during other periods. The degree of time variation is determined by the threshold for each coefficient separately, which is a strong feature of the model and allows for a great deal of flexibility.

We estimate the above model using Bayesian techniques using 30,000 draws as burn-ins and 10,000 posterior draws for inference. While the latent threshold specification ensures a parsimonious handling of time-variation in the coefficients, we augment it with Bayesian shrinkage priors on the initial state of each coefficient. This facilitates variable selection and should mitigate the risk of overparameterization that is inherent vector autoregressive models. The exact prior specifications are detailed in $\mathrm{A}$ in the appendix section.

${ }^{7}$ Due to the high computational burden, the latent indicators $\left(d_{i j, t}\right)$ are approximated rather than exactly estimated during the Markov chain Monte Carlo sampling (Huber et al., 2019). 


\subsection{Structural identification}

In this section, we outline the empirical strategy to identify euro area monetary policy and FG shocks. For that purpose, we use a combination of zero and sign restrictions and locally identify the shocks in the euro area country model. In the GVAR context, local identification has been proposed in Dees et al. (2007) and applied - among others - in Eickmeier and Ng (2015) and Feldkircher and Huber (2016).

Recall that the euro area country model is indexed by $i=0$ and that we estimate already a structural (Cholesky-type) form of the model. Sign restrictions are then introduced by drawing a $k_{0} \times k_{0}$ rotation matrix $R_{0 t}$ (with $R_{0 t} R_{0 t}^{\prime}=I_{k_{0}}$ ) using the algorithm of Arias et al. (2018).

We pre-multiply Eq. (4) to get

$$
\tilde{Q}_{00, t} y_{i t}=\tilde{A}_{0 p, t} x_{0, t-1}+\tilde{B}_{00, t} x_{0, t}^{*}+\tilde{B}_{01, t} x_{0, t-1}^{*}+\tilde{R}_{i 0, t} \varepsilon_{i t},
$$

with $\tilde{Q}_{00, t}=R_{0 t} Q_{00, t}, \tilde{A}_{01, t}=R_{0 t} A_{01, t}$ and $\tilde{B}_{0 q, t}=R_{0 t} B_{0 q, t}$. Notice that Eq. (12) is observationally equivalent to Eq. (4) and the introduction of the rotation matrix $R_{0 t}$ leaves the likelihood function untouched. In addition, notice that the rotation matrices are time-varying and we thus need to simulate $T$ rotation matrices in order to identify the model for each time point. The main implication of local identification in the GVAR context is that the obtained responses are only orthogonal in the country where the shock is applied (i.e., the euro area). For all other countries, the responses are of the generalized form, as in Dees et al. (2007). This implies that the international responses capture the direct spillover effect, effects via third-countries and the domestic responses to these effects.

We identify the two shocks based on the restrictions outlined in Tab. 1 below:

Table 1: Sign restrictions.

\begin{tabular}{lll}
\hline Shock & $i^{s}(M P)$ & $i^{s, t+12}(F G)$ \\
\hline$i_{s}$ & $\uparrow_{1,2}$ & $0_{1}, \operatorname{IRF}\left(i^{s}, 13\right)=\operatorname{IRF}\left(i^{s, t+12}, 1\right)$ \\
$y$ & $\downarrow_{1,2}$ & $\operatorname{IRF}(y, 13)=\operatorname{IRF}\left(y^{t+12}, 1\right)$ \\
$D p$ & $\downarrow_{1,2}$ & $\operatorname{IRF}(D p, 13)=\operatorname{IRF}\left(D p^{t+12}, 1\right)$ \\
$e q$ & $\downarrow_{1,2}$ & $\downarrow_{1,2}$ \\
\hline$i^{s, t+12}$ & - & $\uparrow_{1,2}$ \\
$y^{t+12}$ & - & $\downarrow_{1,2}$ \\
$D p^{t+12}$ & - & $\downarrow_{1,2}$ \\
\hline \multicolumn{2}{l}{ Notes: The sign restrictions are imposed as $\geq / \leq$ and on impact and the following period. } \\
The zero restriction is imposed on impact only. Rotation matrices drawn following Arias \\
et al. (2018).
\end{tabular}

First, an unexpected increase in euro area interest rates $\left(i^{s}\right)$ is supposed to decrease output growth $(y)$, consumer price inflation $(D p)$ and equity returns $(e q)$. These restrictions imply that we rule out counterintuitive reactions of prices and output by construction. ${ }^{8}$ Note that in general, the inclusion

${ }^{8}$ The early literature on monetary policy shocks often focused on the US economy and recursive identification (e.g., Christiano et al., 2005). More recently, a number of authors propose the use of external instruments, high frequency information (Gertler and Karadi, 2015; Altavilla et al., 2019). Miranda-Agrippino and Ricco (2015), however show that using these measures often lead to output and / or price puzzles. 
of expectations data should mitigate the potential of price puzzles (Castelnuovo and Surico, 2010) and introduces additional information to the analysis otherwise not contained in standard macroeconomic data (D'Amico and King, 2015). ${ }^{9}$ The assumption on equity returns is based on empirical evidence for the reaction of stock markets to monetary policy-induced interest rate changes (Thorbecke, 1997; Rigobon and Sack, 2004; Bernanke and Kuttner, 2005; Li et al., 2010). Also, in a recent paper, Jarociński and Karadi (2019) use the movements of equity prices to disentangle "pure" monetary policy shocks from "information" shocks that arise from the central bank's statements about the policy decision. All assumptions are imposed on impact and the following period. The short-horizon of the restrictions and the fact that we use differenced as opposed to level data, ensures that we use a minimum of assumptions and our results are largely data driven. We do not impose restrictions on expectations, nor the Nelson-Siegel yield curve factors.

Second, a forward guidance tightening is modeled as an increase in expected interest rates, while actual rates are unchanged. The following restrictions are based on D'Amico and King (2015) who propose rationality assumptions that help putting more structure on the analysis when dealing with shocks to expectations in a VAR framework. The rationality assumptions we impose ensure that responses of observed output growth, inflation and interest rates match the impact response of their expectations counterparts at the one-year ahead forecast horizon. More specifically, responses of actual interest rates one year ahead (after 13 periods) have to match the interest rate expectation shock on impact. ${ }^{10}$ The same applies to inflation and output growth. Note that these rationality conditions do not impose that expectations are always matched by actual data. Only at the forecast horizon (one year) they have to coincide. To be consistent with the monetary policy shock, we again pursue a weak identification strategy and abstain from placing further restrictions on, say the yield curve (see, e.g., Andrade and Ferroni, 2018).

\section{EMPIRICAL RESULTS}

In this section, we discuss the empirical results of the euro area monetary policy and the interest expectation / forward guidance shocks. We estimated the model presented in section 3 using mean-standardized data. The results below consider the responses of a standard deviation shock in interest rates and interest rate expectations in terms of standard deviations of the variable under scrutiny.

\subsection{Domestic effects}

We start with focusing on the domestic, euro area effects. These are depicted in Figures 3 to 4 . In each plot we show the the posterior median response of each point in our sample. Lighter, yellow responses refer to the beginning of the sample, darker, red responses to the end of the sample. A continuous increase in the shade of a response thus reflects a gradually increasing effect on a particular variable. We also show

${ }^{9}$ Recently, Bu et al. (2020) made the case that to capture forward looking monetary policy it is best to include central bankers' forecasts as opposed to market based expectations for the USA.

${ }^{10}$ D'Amico and King (2015) impose an average restriction on interest rate, while an end-point restriction on output and inflation. The difference arises since they use expectations of interest rates that refer to the average of the next year while one-year ahead forecasts of output and inflation. In our study, forecast data on interest rates also refers to one year ahead and not to the average over the next year. 
the posterior median of the time-averaged responses (solid, black line) along with $68 \%$ credible intervals. The time-averaged responses give a good, first impression of the size and significance of an estimated effect. In general, by averaging over time, we reduce one dimension of uncertainty. Hence, a significant time-averaged response does not necessarily imply that all the underlying, time-varying responses are significant at the same level.

Looking at the euro area monetary policy shock we find persistent negative effects on both inflation and output growth. Regarding the latter, the color shading of the impulses suggest that the middle segment of the sample span shows a more pronounced rebound than the rest of the sample. In line with responses of actual output growth and inflation, expectations are also persistently negative. These results are purely data driven since we did not put restrictions on expectations for the monetary policy shock. Interest rates turn negative after about 5 months, while interest rate expectations are persistently negative from the first period onward. Equity prices show the most pronounced, negative reaction, which is precisely estimated up to 4 periods. Looking at movements of the yield curve, we find a positive effect on the inverse slope coefficient $\left(\beta^{1}\right)$ suggesting a flattening of the yield curve which is typical after a monetary policy tightening. The reason is that the rate increase at the short-end is not fully passed on to the long end of the curve (Benati and Goodhart, 2008). Here, additional downward pressure on the long-end of the curve stems from the negative reaction of inflation expectations. We also find a significant and negative response of the curvature factor $\left(\beta^{2}\right)$, which implies less mass of the yield curve in the medium-term segment and more in the short-end. There is no significant response of the MPC communicator control variable.

Next, we investigate the responses to an increase in interest rate expectations. These are displayed in Fig. 4.

The interest rate expectation shock triggers a downward movement of output growth and inflation expectations. Both effects are rather persistent, although the restrictions have been placed only on the first two periods. Responses of actual output growth and inflation are also persistently negative. In some periods of the sample span, the median responses of inflation tend to be positive, but on impact only. Both, responses of interest rate expectations and actual interest rates are persistently positive. The shape of interest rate responses differs from the one for the conventional monetary policy shock where interest rates turned negative after some periods. Consistent with responses to the monetary policy shock, the most pronounced responses are those of equity returns. These are even more persistent for the interest rate expectations shock. The yield curve factors imply that the slope of the curve also flattens, but the curvature factor is positively affected. There is a broad literature that shows that forward guidance mostly affects the middle segment of the yield curve. For example, Rogers et al. (2014), state that FG does typically not affect yields with larger maturity as 5 years and more explicitly Brand et al. (2010) reports a hump-shaped maturity response pattern of euro area yields to communication. Also more recently, Altavilla et al. (2019) using high frequency identification show that FG affects yields with a maturity over 2 years most strongly. 
Fig. 3: Euro area responses to a euro area monetary policy tightening

(a) Short-rates

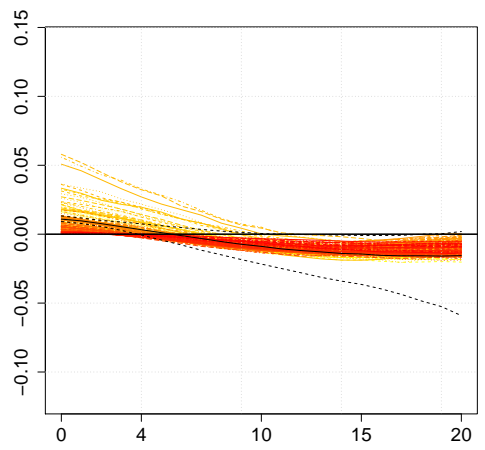

(d) GDP expectations

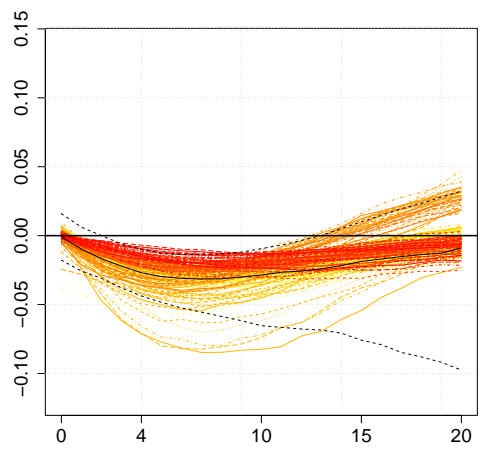

(g) $\beta_{0}$

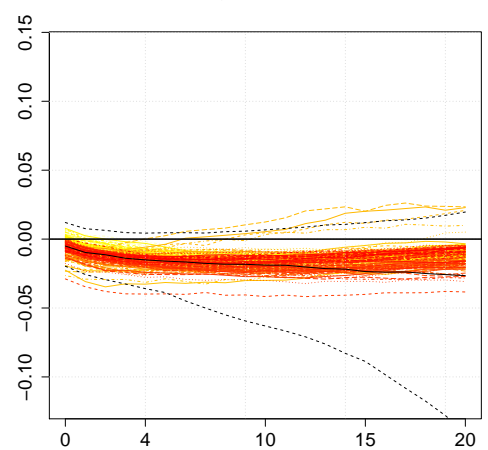

(j) Equity returns

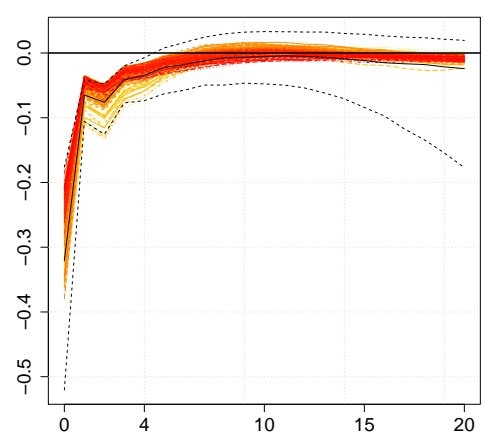

(b) Output growth

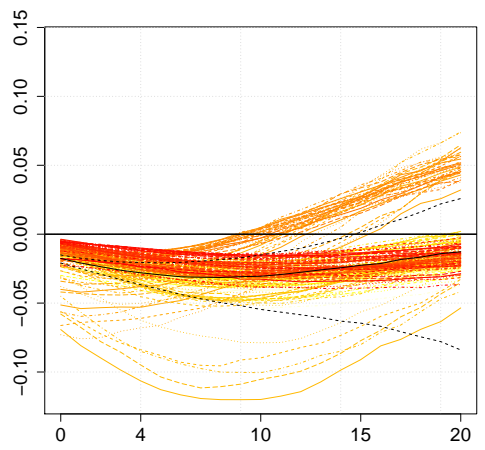

(e) Inflation expectations

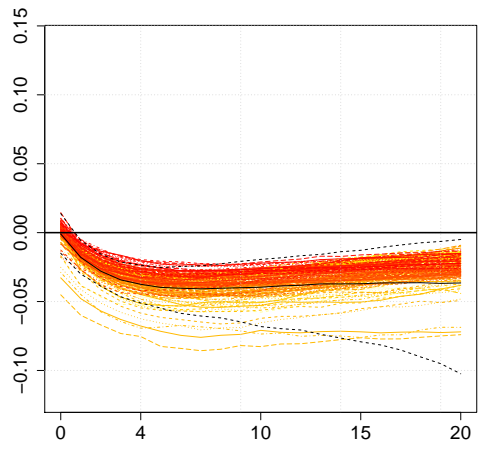

(h) $\beta_{1}$

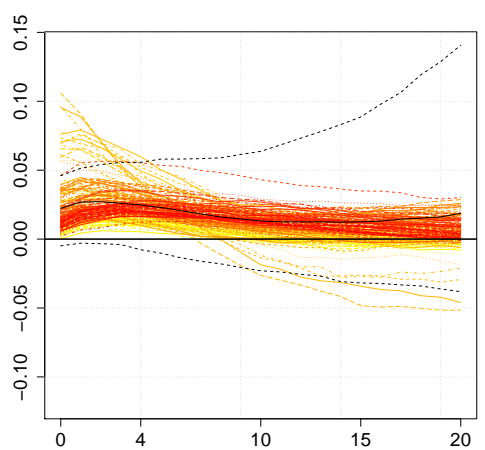

(k) MPC communicator

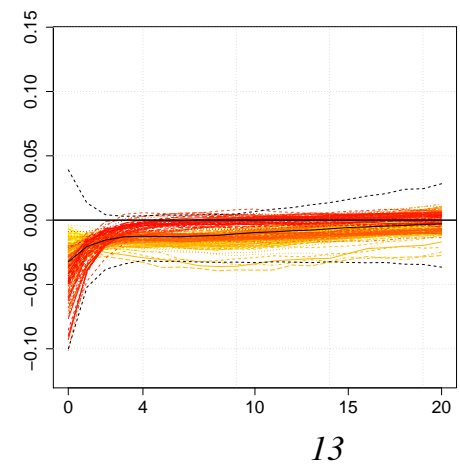

(c) CPI inflation

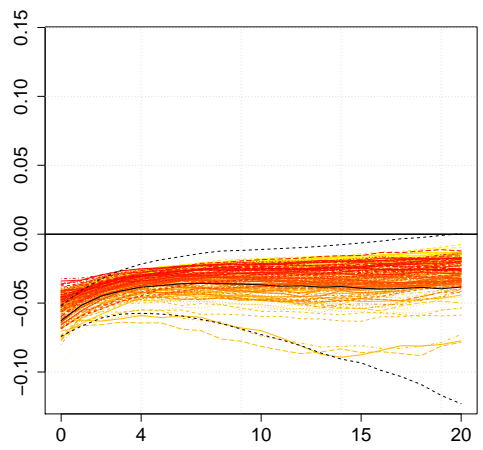

(f) Interest rate expectations

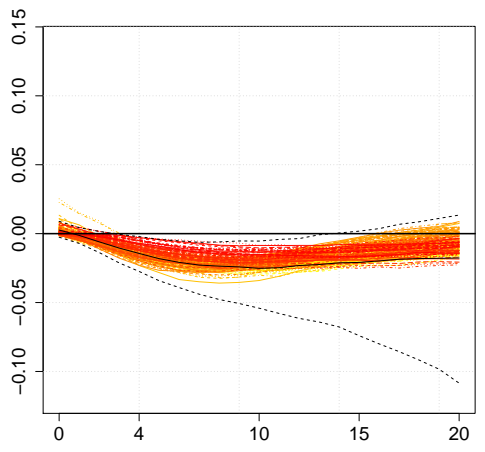

(i) $\beta_{2}$

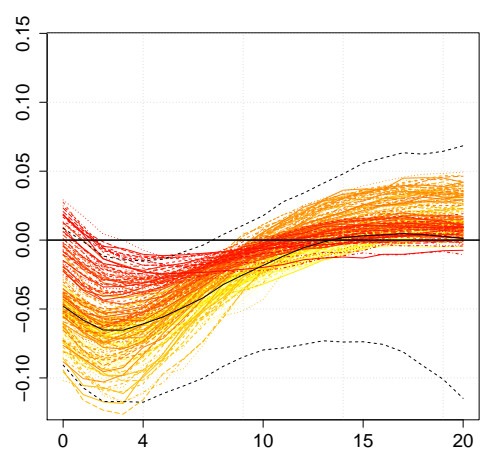

Notes: The plot shows posterior median responses over the sample period. Light yellow responses correspond to the beginning of the sample (i.e., 2001m1), dark red responses to the end (i.e., 2018m6). The black line corresponds to the posterior median of the time averaged response along with $68 \%$ credible bounds. 
Fig. 4: Euro area responses to a euro area forward guidance tightening

(a) Short-rates

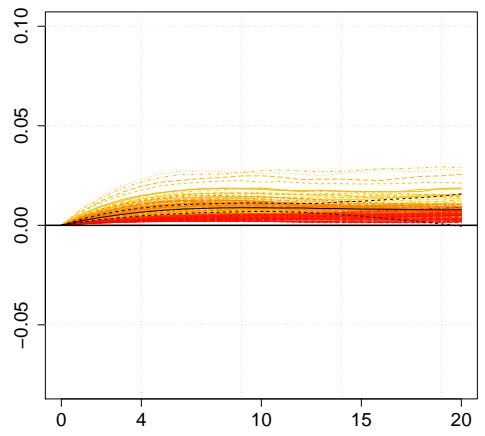

(d) GDP expectations

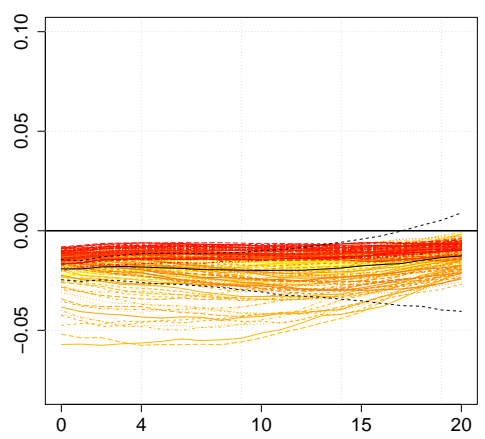

(g) $\beta_{0}$

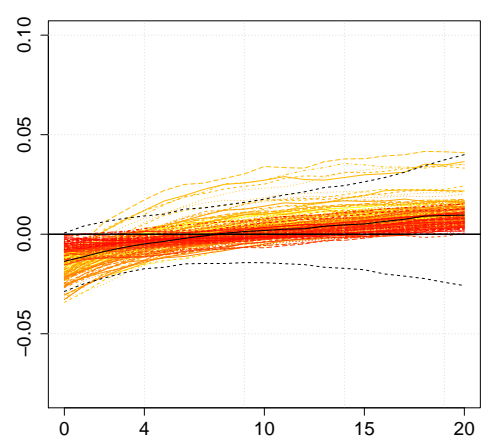

(j) Equity returns

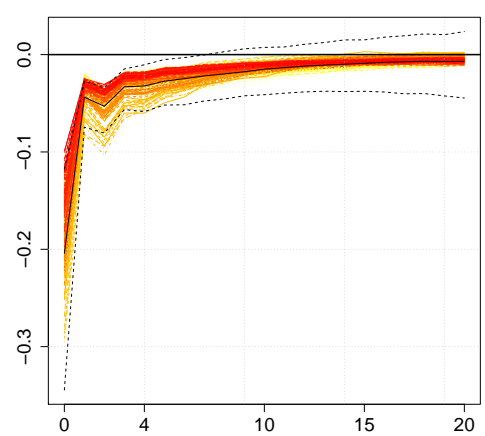

(b) Output growth

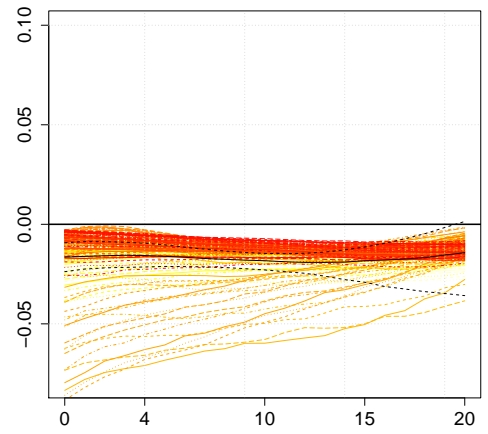

(e) Inflation expectations

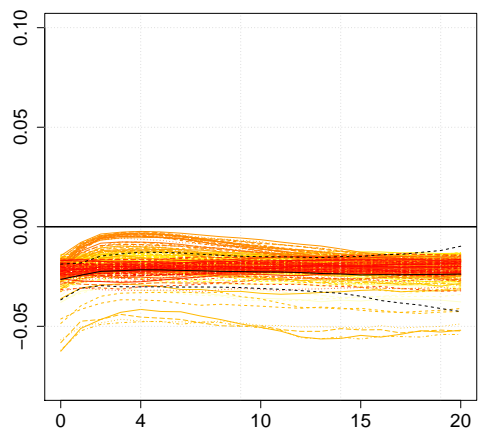

(h) $\beta_{1}$

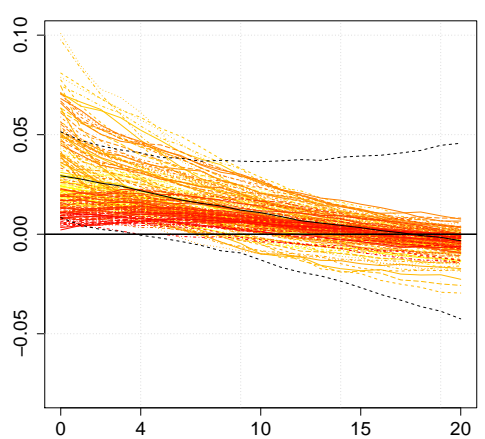

(k) MPC communicator

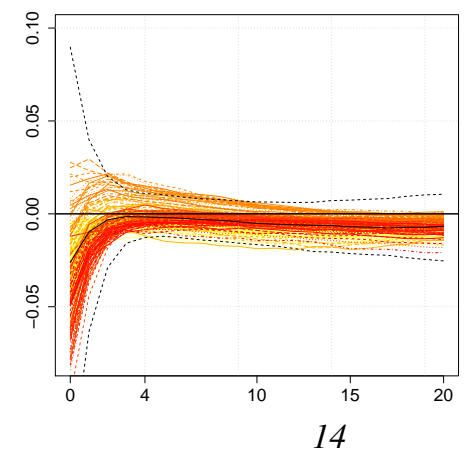

(c) CPI inflation

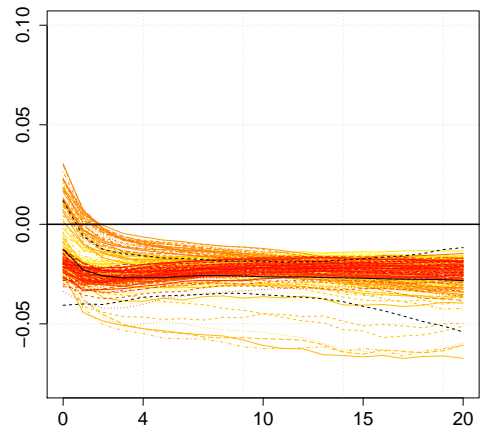

(f) Interest rate expectations

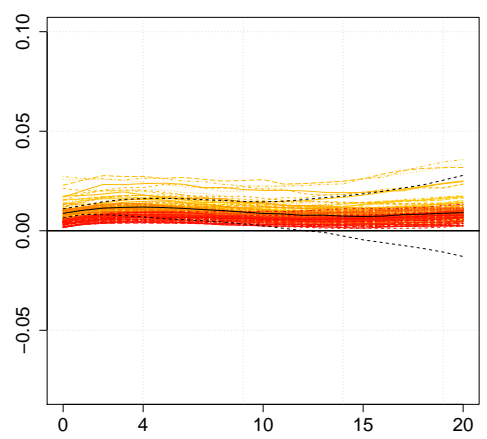

(i) $\beta_{2}$

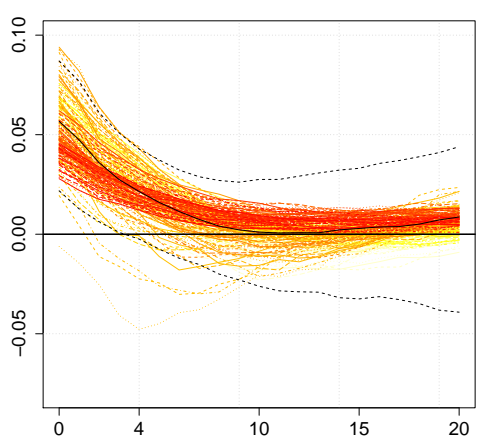

Notes: The plot shows posterior median responses over the sample period. Light yellow responses correspond to the beginning of the sample (i.e., 2001m1), dark red responses to the end (i.e., 2018m6). The black line corresponds to the posterior median of the time averaged response along with $68 \%$ credible bounds. 


\subsection{International effects}

In this section we examine the effects of the euro area shocks on its neighboring countries. To get a first impression of the extent of spillovers, we focus on the averaged responses over the sample span. The significant peak values of the time-averaged effects are summarized in Fig. 5.

The left-hand side of the upper panel of Fig. 5 shows that the conventional monetary policy tightening shock negatively affects international output growth, inflation, long-term interest rates and equity returns for most economies. Not surprisingly, spillovers to equity returns are most pronounced, given the strong domestic effects on stock market returns in the euro area. Some cross-country variation is evident for exchange rates. Exchange rates in euro area neighboring countries (e.g., Hungary, Czechia, Poland, Sweden) respond positively to the rate increase, indicating a depreciation of local currencies against the euro. For these economies, the preservation of export competitiveness is essential given their strong trade ties with the euro area. For other major economies, such as Japan, Canada and the USA, local currencies appreciate against the euro. The right hand-side of the upper panel of Fig. 5 shows the peak effects in response to the FG tightening. The picture shows that in general, responses are very similar to a standard rate increase: international output growth, inflation and equity returns decrease. Also in line with the conventional monetary policy shock, countries differ in their response via the exchange rate but peak effects tend to be less precisely estimated. Compared to the conventional rate increase, peak responses of long-term interest rates are mostly insignificant. This difference might arise due to the distinct behavior of the euro area yield curve under the two shock scenarios.

The bottom panel of Fig. 5 shows the timing of the peak responses. Some of them are variablespecific. For example, while peak effects of spillovers to equity prices occur immediately, spillovers to output growth are more persistent and peak at about 10 to 15 months. For other variables, however, the timing of the effects is more country-specific. More specifically, responses of inflation, exchange rates and long-term interest rates of close neighbors of the euro area (e.g., Czechia, Hungary, Poland, Norway, Romania) show a faster reaction as major, global economies (e.g., China, Japan, USA). This implies that geographical proximity determines the speed of spillover transmission. In comparison with responses to the conventional rate hike, responses to the interest rate expectation shock are more delayed (right-hand side of bottom panel of Fig. 5). This might be a direct results of the more persistent interest rate response in the euro area.

Next, we consider effects over the full sample period. As a summary measure, we calculate the area under the curve from the posterior median to the origin. We do this for all responses that are significant according to the $68 \%$ credible intervals. We calculate the area from the posterior median (as opposed to calculating it from either the 16 or 84 th percentile) since the median is the most commonly used point estimate to quantify the effects of a shock. The full set of responses for all countries and variables are shown in the appendix in figures Fig. C.1 to Fig. C.12.

Fig. 6 shows the area under the curve (AUC) of reactions to the two shocks.

We first investigate international responses to the conventional monetary tightening, provided in the top panel of Fig. 6. Recall that structural generalized impulse responses in a GVAR framework reflect the direct (spillover) effects, indirect effects via third-countries, as well as the domestic response to the shock of a given country. Nevertheless, the figure shows that most responses are negative. This holds true for output growth, inflation and equity returns. In some cases, also exchange rates depreciate against the euro 
Fig. 5: Heat map of peak effects (time-averaged responses)

(a) Peak effects

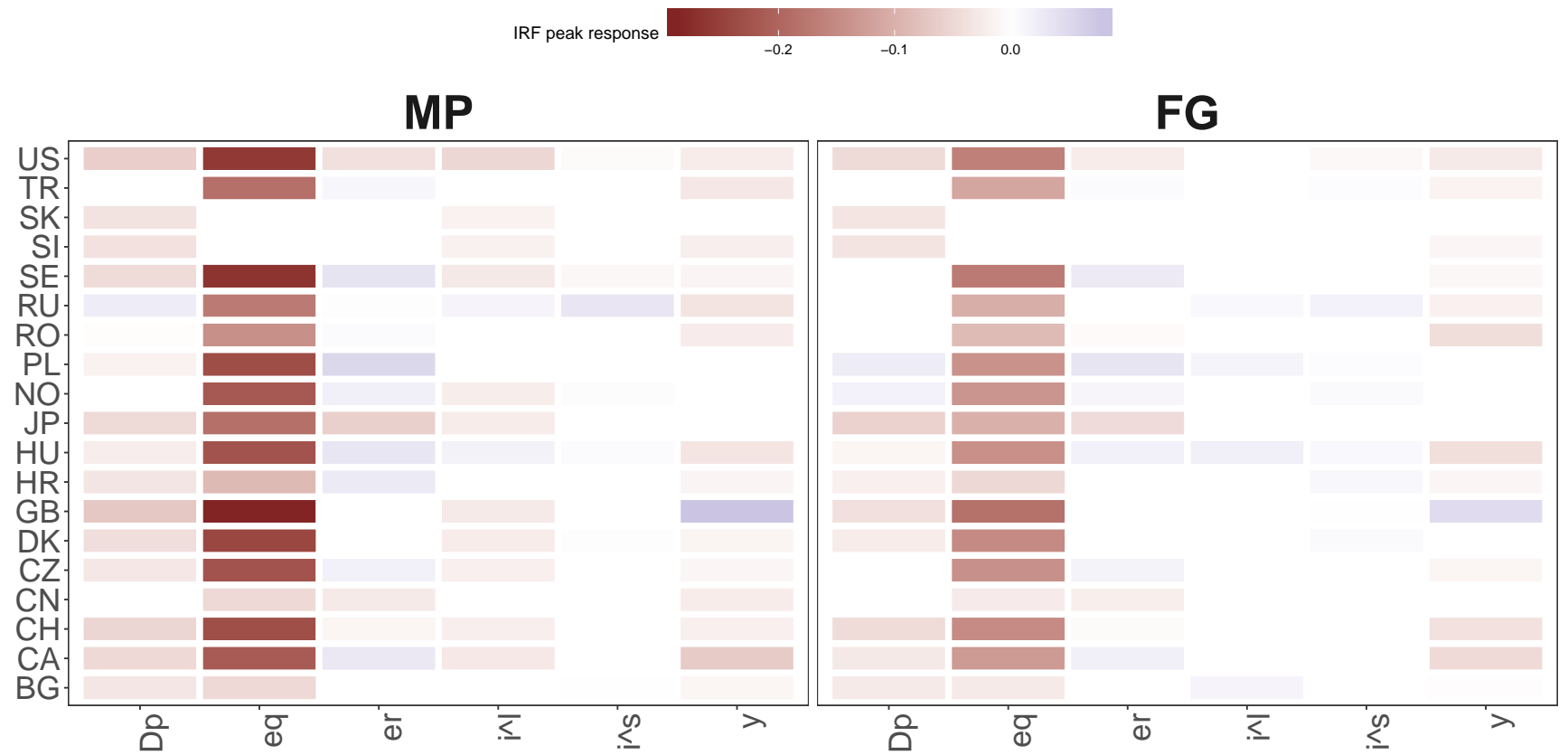

(b) Timing of peak effects

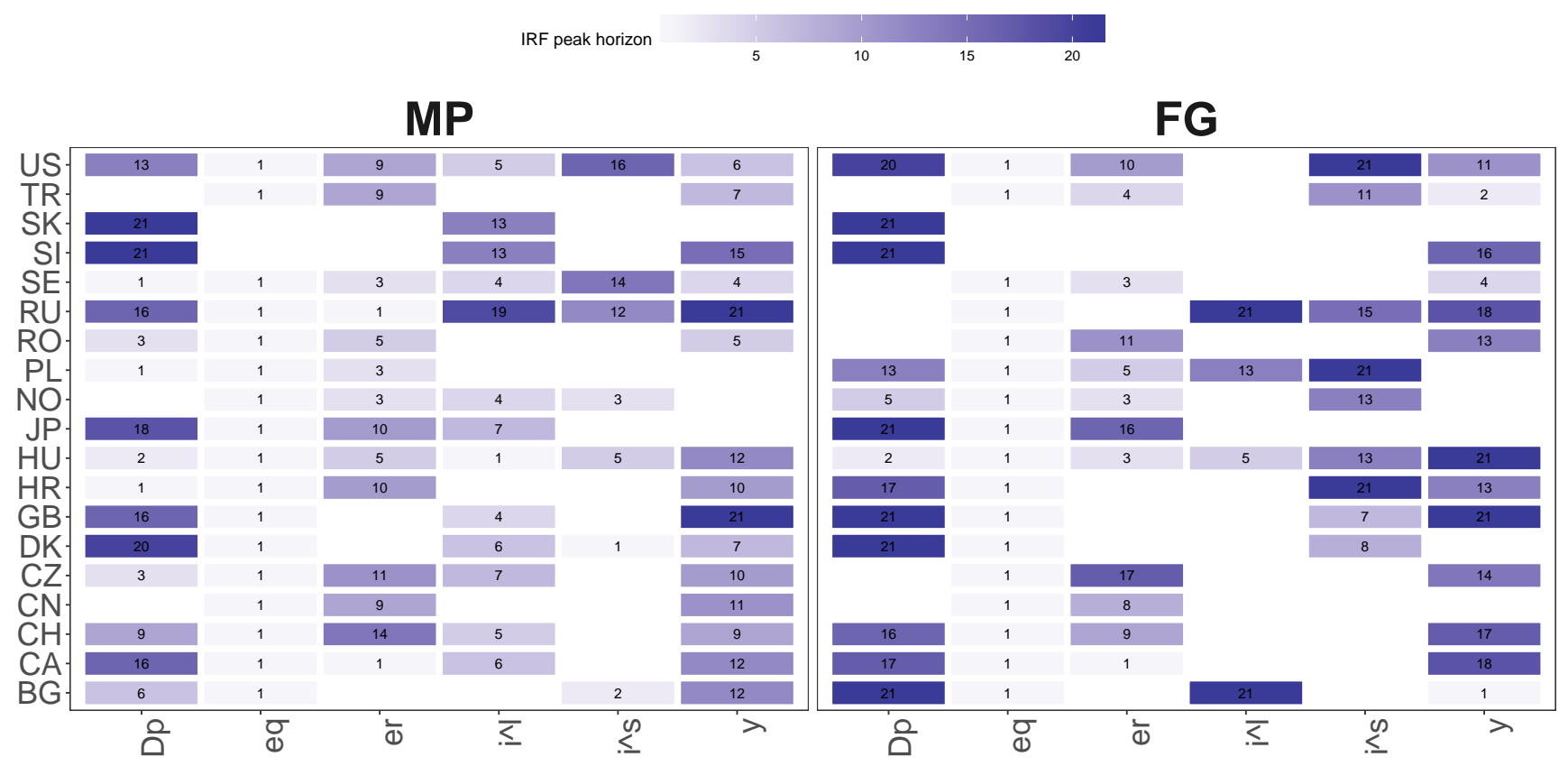

Notes: The plot shows a heat map of peak values of the time-averaged responses (top panel) and timing of the peaks (bottom panel). 
Fig. 6: Area under the curve of significant international responses

(a) Monetary policy tightening $\left(i^{s}\right)$

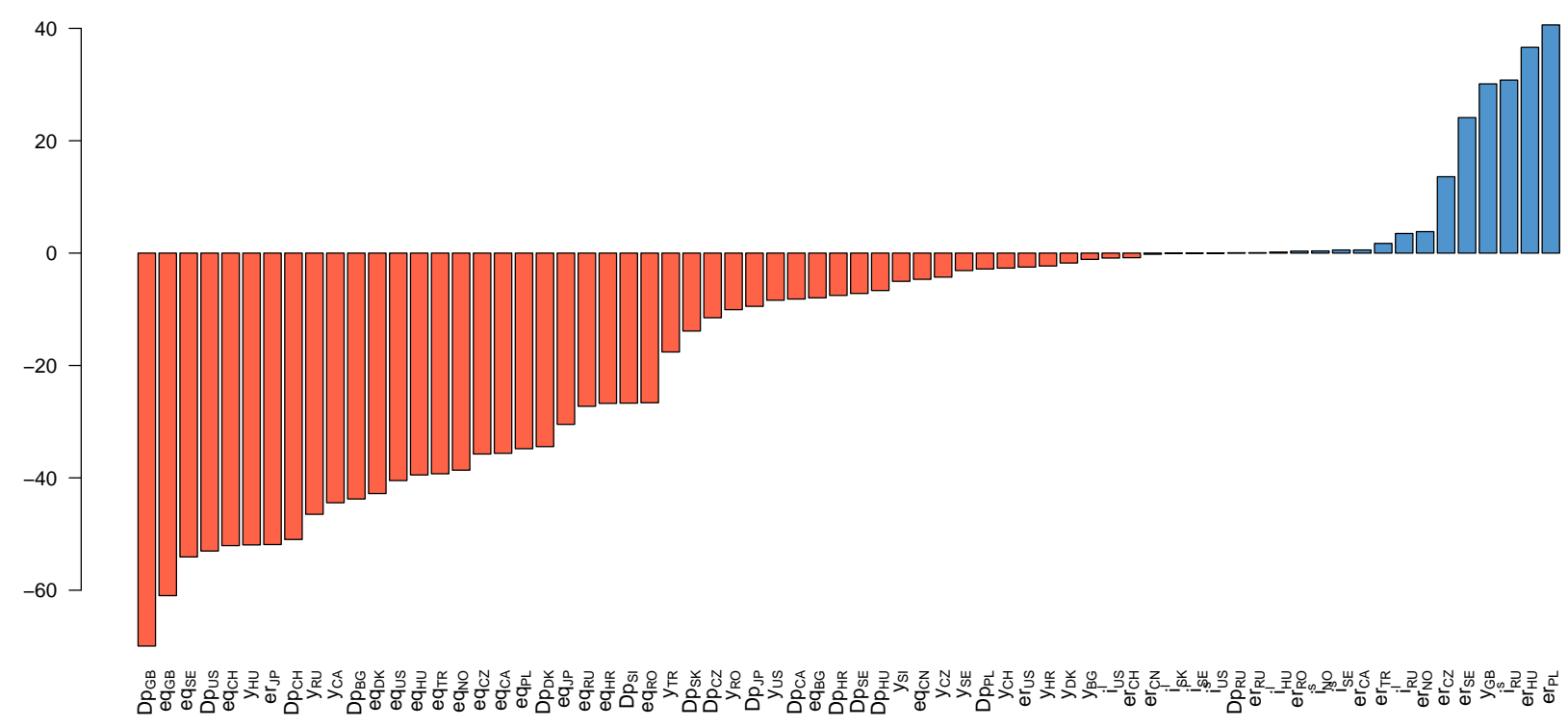

(b) Forward guidance tightening $\left(i^{s, t+12}\right)$

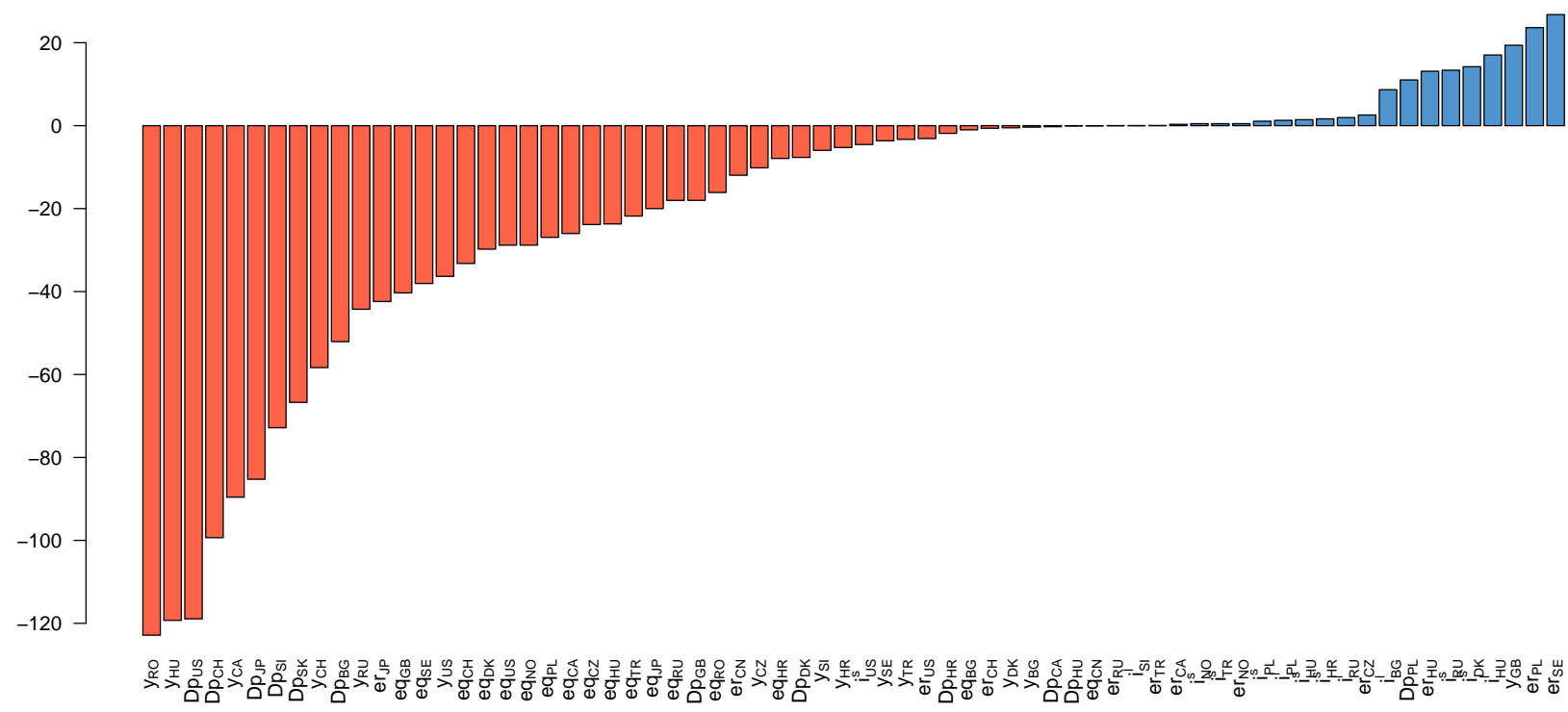

Notes: The plot shows the area under the curve, calculated from the posterior median to the origin, over impulse response horizons that are significant according to the $68 \%$ credible intervals. The areas under the curve are summed over all time periods in the sample. Red bars indicate negative (total) areas, blue bars positive (total) areas. 
and interest rates ease. The latter finding is in line with predictions of standard open-economy DSGE models which suggest that, if the country where the monetary policy shock originates is large relative to the spillover receiving economies, domestic interest rates can ease triggered indirectly via a decline in world interest rates (Svensson and van Wijnbergen, 1989; Galí and Monacelli, 2005). Currencies weaken against the euro in European, neighboring countries (e.g., Czechia, Hungary, Poland, Norway, Sweden, Romania), but also in Canada, Russia and Turkey. More generally, the countries affected range from neighboring countries of the euro area to major, international economies such as the USA. This also carries over to financial variables such as equity returns indicating that euro area shocks can have far reaching consequences. Some countries deviate from the general, international pattern. For example, in Great Britain we find a positive peak effect on output growth and a negative peak effect on inflation. This resembles the reaction of a negative domestic supply shock. Also, in Russia, interest rates increase sharply, probably as a reaction to fight the acceleration in domestic inflation. The strong domestic policy response in turn partially explains the steep decline in output growth.

Next, we examine responses to the increase in expected interest rates. Again, responses are mostly negative, implying that the FG shock deters international output growth, inflation and equity returns. Compared to international reactions to the conventional monetary policy shock, the area under the curve in response to an increase in interest rate expectations are generally larger. This implies that either, responses to $i^{s, t+12}$ exceed those to $i^{s}$ in terms of magnitude or are estimated with larger precision (yielding hence more periods and forecast horizons to integrate the respective area). Figure C.13 in the appendix suggests that effects of the interest rate expectations shock are generally smaller, hence the difference in the area under the curve results from more precisely estimated responses. Another difference compared to spillovers from the conventional monetary policy shock can be seen by looking at interest rates. There are more positive reactions of both short- and long-term interest rates, which might be related to the more persistently positive domestic reaction of euro area short-term interest rates.

\subsection{Do effects differ over the sample period?}

Next, we investigate in more detail whether domestic and spillover effects vary considerably over time. For that purpose we calculate the area under the curve, aggregated per variable. The results are provided in Fig. 7.

Focusing on the responses to the conventional monetary policy shock first, we see that effects are strongest / most precisely estimated for financial variables at the end of 2008, i.e., in the midst of the global financial crisis. Effects on real variables peak a bit later (around the beginning of 2009). With the exception of interest rates, effects in the aftermath of the crisis are much smaller / less precisely estimated compared to the crisis peak. This pattern differs when considering the FG shock, displayed in the right column of Fig. 7. Here, we have also a peak around the global financial crisis but in addition effects persist also in the aftermath of the crisis. This finding is consistent with monetary policy actions over that period: Whereas interest rates did not change since 2012 (due to the zero lower bound), the ECB launched monetary policy measures geared towards changing interest rate expectations, such as forward guidance, over the most recent period in our sample. Also note that, while certainly communication of the central bank did affect interest rate expectations prior the official implementation of rate FG in 2013, its effects seem particularly pronounced over periods when conventional monetary policy is absent. 
Fig. 7: Area under the curve over time

(a) Output growth (MP)

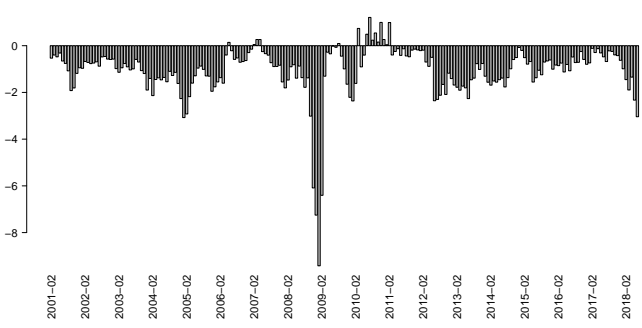

(c) Inflation (MP)

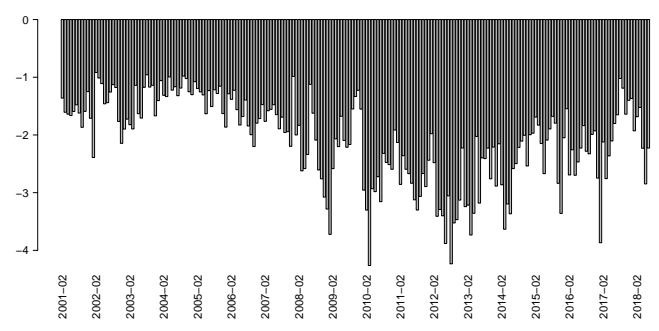

(e) Short-rates (MP)

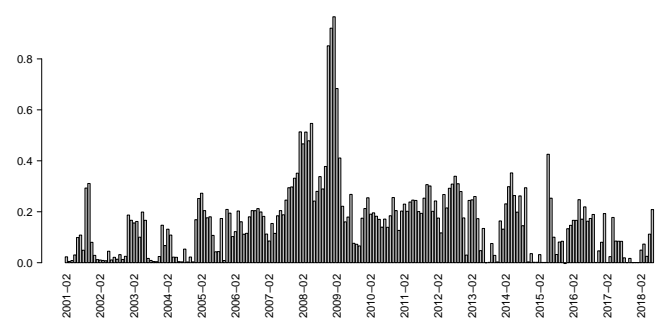

(b) Output growth (FG)

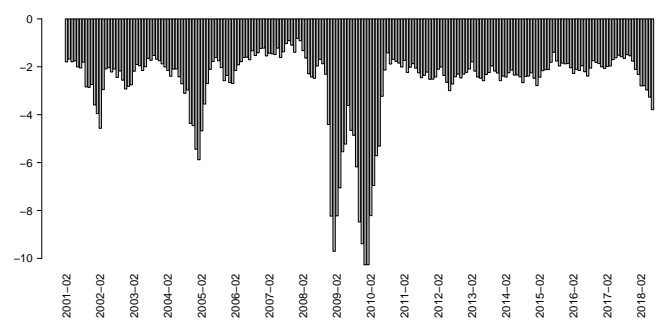

(d) Inflation (FG)

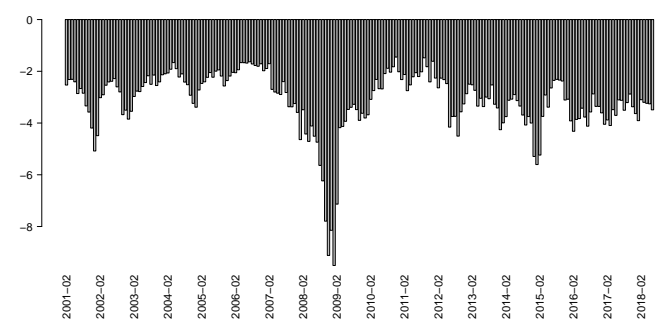

(f) Short-rates (FG)

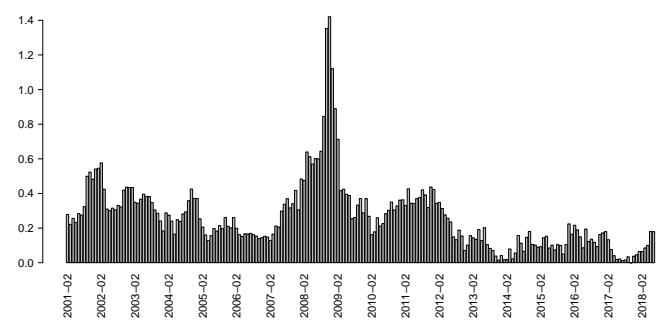

Notes: The plot shows the area under the curve, calculated from the posterior median to the origin, over impulse response horizons that are significant according to the $68 \%$ credible intervals per variable and over time.

\section{CONCLUSIONS}

In this paper, we investigate the domestic and international effects of euro area forward guidance shock, which we model by a change in expected interest rates. To gauge the importance of FG, we compare these effects to those of a standard, conventional monetary policy shock that works through a change in actual interest rates. Both shocks are identified using a combination of zero and sign restrictions and the recently proposed rationality conditions of D'Amico and King (2015) which put structure on the joint behavior of impulse responses of actual and expectations data.

Our principal conclusions are as follows: First, a conventional and contractionary monetary policy shock in the euro area triggers a broad based deceleration in domestic and international output growth, inflation and equity returns. Domestic negative responses are amplified by negative output growth and 
Fig. 8: Area under the curve over time

(a) Equity returns (MP)

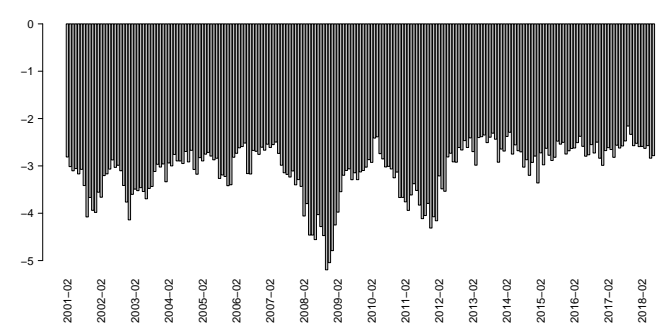

(c) Exchange rates (MP)

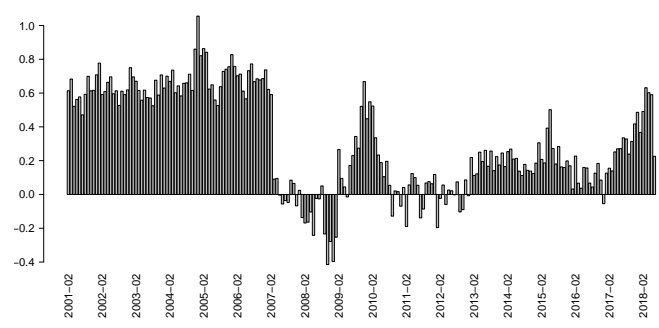

(e) Long-rates (MP)

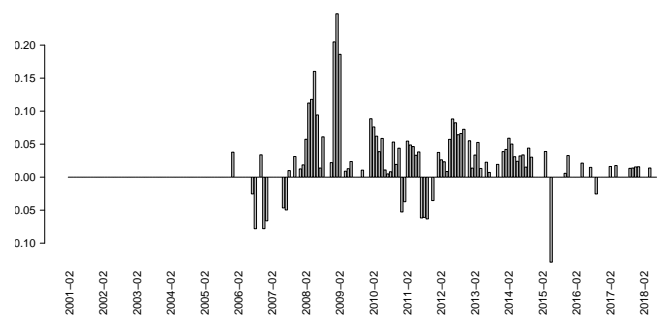

(b) Equity returns (FG)

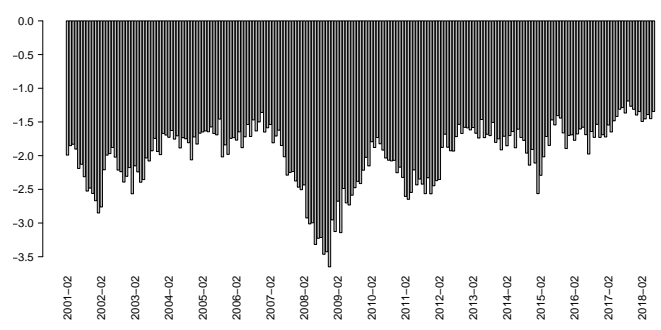

(d) Exchange rates (FG)

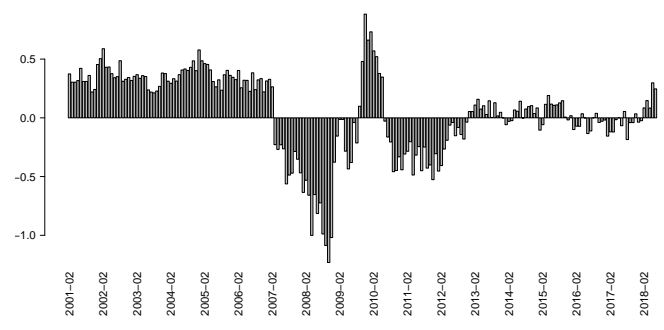

(f) Long-rates (FG)

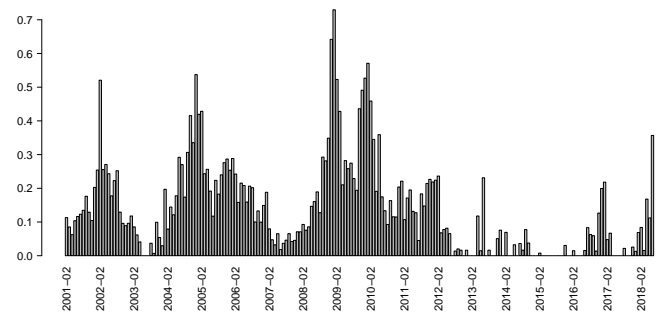

Notes: The plot shows the area under the curve, calculated from the posterior median to the origin, over impulse response horizons that are significant according to the $68 \%$ credible intervals per variable and over time.

inflation outlooks for the euro area. Our results also indicate strong, negative effects on equity returns. However, in contrast to the remaining variables, these are rather short-lived. Exchange rate responses are country-specific with currencies of euro area's neighbors tending to weaken against the euro.

Second, we investigate the international effects of an increase in euro area interest rate expectations, while actual interest rates remain zero on impact. This FG shock yields mostly similar responses as the conventional monetary policy shock: Domestic and international output growth and inflation decelerate and equity returns decline. Compared to effects of the conventional monetary policy shock, we find more positive effects on international interest rates. This might be related to the domestic response of euro area interest rates, which is more persistent for the FG shock.

Last, we find evidence of time variation for both shocks. Effects of a conventional monetary policy are larger/precisely estimated around the time of the global financial crisis, while effects abate thereafter. 
FG, by contrast, shows also precisely estimated effects in the aftermath of the crisis. This finding might be related to the zero lower bound which limits the effectiveness of conventional monetary policy, whereas rate FG can still be a stimulating monetary policy tool.

Our careful and exhaustive analysis suggests that FG is a powerful tool and even more so in crisis conditions. Of course, not all crises are of the financial variety. As this is written, with a new crisis underway, how central banks manage interest rate expectations is set to become even more important. We have focused on restrictions that impact the short-end of the term structure. A natural extension is to more explicitly consider the case of yield curve control, already introduced in Japan and being considered in the USA and perhaps the euro area.

While the distinction between Delphic and Odyssean forward guidance is helpful to fix ideas, our results demonstrate that FG can be effective regardless of the manner it is portrayed. Finally, while our estimates capture central banks' imperfect credibility over time, there is no explicit modelling of the feedback relationship between central bank actions and expectations. An additional extension might consist in asking what would the impact of FG be if credibility was modeled differently. We leave these extensions for future research.

\section{REFERENCES}

Altavilla C, Brugnolini L, Gürkaynak RS, Motto R, Ragusa G. 2019. Measuring euro area monetary policy. Journal of Monetary Economics 108: 162-179.

Andrade P, Ferroni F. 2018. Delphic and Odyssean monetary policy shocks: Evidence from the euro-area. Working Paper WP-2018-12, Federal Reserve Bank of Chicago.

Arias JE, Rubio-Ramírez JF, Waggoner DF. 2018. Inference based on structural vector autoregressions identified with sign and zero restrictions: Theory and applications. Econometrica 86: 685-720.

URL https://onlinelibrary.wiley.com/doi/abs/10.3982/ECTA14468

Benati L, Goodhart C. 2008. Investigating time-variation in the marginal predictive power of the yield spread. Journal of Economic Dynamics and Control 32: 1236-1272.

URL http://ideas.repec. org/a/eee/dyncon/v32y2008i4p1236-1272.html

Bernanke BS, Kuttner KN. 2005. What explains the stock market's reaction to federal reserve policy? Journal of Finance 60: 1221-1257.

Bordo M, Siklos P. 2018. Sveriges Riksbank and the History of Central Banking (Studies in Macroeconomic History, chapter Central Banks: Evolution and Innovation in Historical Perspective. Cambridge: Cambridge University Press, 26-89.

Bordo M, Siklos P. 2019. The Transformation and Performance of Emerging Market Economies Across the Great Divide of the Global Financial Crisis. Working paper 26342, NBER.

Brand C, Buncic D, Turunen J. 2010. The impact of ECB monetary policy decisions and communication on the yield curve. Journal of the European Economic Association 8: 1266-1298.

$\mathrm{Bu} \mathrm{C}$, Rogers J, Wu W. 2020. Forward-looking monetary policy and the transmission of conventional monetary policy shocks. Finance and Economics Discussion Series 2020-014, Federal Reserve Board, Washington, D.C.

Bundick B, Smith AL. 0. The dynamic effects of forward guidance shocks. The Review of Economics and Statistics 0: $1-45$.

URL https://doi.org/10.1162/rest_a_00856

Burriel P, Galesi A. 2018. Uncovering the heterogeneous effects of ecb unconventional monetary policies across euro area countries. European Economic Review 101: 201-229.

URL https: //ideas . repec .org/p/bde/wpaper/1631.html

Callum J, Kulish M, Rees D. 2018. International spillovers of forward guidance shocks. Working Paper WP/18/114, IMF. 
Campbell JR, Evans CL, Fisher JDM, Justiniano A. 2012. Macroeconomic Effects of Federal Reserve Forward Guidance. Brookings Papers on Economic Activity 3: 1-80.

URL https://www.brookings .edu/wp-content/uploads/2012/03/2012a_Evans.pdf

Castelnuovo E, Surico P. 2010. Monetary policy, inflation expectations and the price puzzle. The Economic Journal 120: $1262-1283$.

URL https://onlinelibrary.wiley.com/doi/abs/10.1111/j.1468-0297.2010.02368.x

Chow G, Lin A. 1971. Best linear unbiased interpolation, distribution, and extrapolation of time series by related series. Review of Economics and Statistics 53: 372-375.

Christiano LJ, Eichenbaum M, Evans CL. 2005. Nominal rigidities and the dynamic effects of a shock to monetary policy. Journal of political Economy 113: 1-45.

Crespo Cuaresma J, Doppelhofer G, Feldkircher M, Huber F. 2019. Spillovers from US monetary policy: evidence from a time varying parameter global vector auto-regressive model. Journal of the Royal Statistical Society: Series A 182: 831-861.

URL https://rss.onlinelibrary.wiley.com/doi/abs/10.1111/rssa. 12439

D’Amico S, King TB. 2015. What Does Anticipated Monetary Policy Do? Working Paper Series WP-2015-10, Federal Reserve Bank of Chicago.

URL https://ideas.repec.org/p/fip/fedhwp/wp-2015-10.html

de la Barrera M, Falath J, Henricot D, Vaglio J. 2017. The impact of forward guidance on inflation expectations: Evidence from the ecb. Working paper series 1010, Barcelona graduate school of economics working paper series.

Dees S, di Mauro F, Pesaran HM, Smith LV. 2007. Exploring the international linkages of the euro area: a global VAR analysis. Journal of Applied Econometrics 22.

Diebold FX, Li C. 2006. Forecasting the term structure of government bond yields. Journal of Econometrics 130: 337-364.

URL https://ideas.repec.org/a/eee/econom/v130y2006i2p337-364.html

Diebold FX, Rudebusch GD, Aruoba SB. 2006. The macroeconomy and the yield curve: a dynamic latent factor approach. Journal of Econometrics 131: 309-338. ISSN 0304-4076.

URL http://www. sciencedirect.com/science/article/pii/S030440760500014X

Ehrmann M, Gaballo G, Hoffmann P, Strasser G. 2019. Can more public information raise uncertainty? the international evidence on forward guidance. Journal of Monetary Econometrics : forthcoming.

URL https://onlinelibrary.wiley.com/doi/abs/10.1002/jae.1173

Eickmeier S, Ng T. 2015. How do US credit supply shocks propagate internationally? A GVAR approach. European Economic Review 74: 128 - 145. ISSN 0014-2921.

URL http://www. sciencedirect.com/science/article/pii/S0014292114001652

Feldkircher M, Gruber T, Huber F. 2019. International effects of a compression of euro area yield curves. Journal of Banking \& Finance : forthcoming.

Feldkircher M, Huber F. 2016. The international transmission of US shocks - Evidence from Bayesian global vector autoregressions. European Economic Review 81: 167-188.

URL https://ideas.repec.org/a/eee/eecrev/v81y2016icp167-188.html

Filardo A, Hofmann B. 2014. Forward guidance at the zero lower bound. BIS Quarterly Review . URL https://ideas.repec.org/a/bis/bisqtr/1403f.html

Galati G, Poelhekke S, Zhou C. 2011. Did the crisis affect inflation expectations? International Journal of Central Banking 7: 167-207.

URL https://www.ijcb.org/journal/ijcb11q1a8.pdf

Galí J, Monacelli T. 2005. Monetary policy and exchange rate volatility in a small open economy. Review of Economic Studies 72: 707-734.

Georgiadis G. 2015. Examining asymmetries in the transmission of monetary policy in the euro area: Evidence from a mixed cross-section global var model. European Economic Review 75: 195-215.

URL http://EconPapers.repec.org/RePEc : eee : eecrev:v: $75: y: 2015: i: c: p: 195-215$

Gertler M, Karadi P. 2015. Monetary policy surprises, credit costs, and economic activity. American Economic Journal: Macroeconomics 7: 44-76.

Geweke J. 1992. Evaluating the accuracy of sampling-based approaches to the calculation of posterior moments. In 
Bernardo JM, Berger JO, Dawid AP, Smith AFM (eds.) Bayesian Statistics 4. Oxford University Press, Oxford, pp. 169-193.

Griffin JE, Brown PJ. 2010. Inference with normal-gamma prior distributions in regression problems. Bayesian Analysis 5: 171-188.

Gürkaynak RS, Sack B, Swanson ET. 2015. Do actions speak louder than words? the response of asset prices to monetary policy actions and statements. International Journal of Central Banking 1: 55-93.

Huber F. 2016. Density forecasting using bayesian global vector autoregressions with stochastic volatility. International Journal of Forecasting 32: 818-837.

Huber F, Kastner G, Feldkircher M. 2019. Should I stay or should I go? A latent threshold approach to large-scale mixture innovation models. Journal of Applied Econometrics 34: 621-640.

Hubert P, Labondance F. 2018. The Effect of ECB Forward Guidance on the Term Structure of Interest Rates. International Journal of Central Banking 14: 193-222.

URL https://ideas. repec . org/p/crb/wpaper/2016-12.html

Jarociński M, Karadi P. 2019. Deconstructing monetary policy surprises - the role of information shocks. American Economic Journal: Macroeconomics : forthcoming.

Kastner G, Frühwirth-Schnatter S. 2014. Ancillarity-sufficiency interweaving strategy (asis) for boosting mcmc estimation of stochastic volatility models. Computational Statistics \& Data Analysis 76: 408-423.

Koop G, Korobilis D, Pettenuzzo D. 2019. Bayesian compressed vector autoregressions. Journal of Econometrics 210: $135-154$.

Kortela T, Nelimarkka J. 2020. The effects of conventional and unconventional monetary policy: Identification through the yield curve. Research Discussion Paper 3/2020, Bank of Finland.

Krippner L. 2013. Measuring the stance of monetary policy in zero lower bound environments. Economics Letters 118: $135-138$.

Li YD, Iscan TB, Xu K. 2010. The impact of monetary policy shocks on stock prices: Evidence from canada and the united states. Journal of International Money and Finance 29: 876-896. ISSN 0261-5606. URL http: //www. sciencedirect. com/science/article/pii/S0261560610000422

Miranda-Agrippino S, Ricco G. 2015. The Transmission of Monetary Policy Shocks. Discussion Papers 1711, Centre for Macroeconomics (CFM).

URL https://ideas. repec.org/p/cfm/wpaper/1711.html

Nakamura E, Steinsson J. 2018. High-frequency identification of monetary non-neutrality: The information effect. The Quarterly Journal of Economics 133: 1283-1330.

Nelson CR, Siegel AF. 1987. Parsimonious Modeling of Yield Curves. The Journal of Business 60: 473-489.

Neuenkirch M. 2013. Monetary policy transmission in vector autoregressions: A new approach using central bank communication. Journal of Banking \& Finance 37: 4278-4285.

Pesaran MH, Schuermann T, Weiner SM. 2004. Modeling Regional Interdependencies Using a Global ErrorCorrecting Macroeconometric Model. Journal of Business and Economic Statistics, American Statistical Association 22: 129-162.

Rigobon R, Sack B. 2004. The impact of monetary policy on asset prices. Journal of Monetary Economics 51: $1553-1575$.

Rogers JH, Scotti C, Wright JH. 2014. Evaluating Asset-Market Effects of Unconventional Monetary Policy: A Multi-Country Review. Economic Policy 29: 3-50.

Siklos PL. 2013. Sources of disagreement in inflation forecasts: An international empirical investigation. Journal of International Economics 90: 218-231.

URL https://ideas.repec.org/a/eee/inecon/v90y2013i1p218-231.html

Svensson L, van Wijnbergen S. 1989. Excess capacity, monopolistic competition, and international transmission of monetary disturbances. Economic Journal 397: 785-805.

Thorbecke W. 1997. On stock market returns and monetary policy. Journal of Finance 52: 635-654.

Timmer MP, Dietzenbacher E, Los B, Stehrer R, de Vries GJ. 2015. An Illustrated User Guide to the World Input-Output Database: the Case of Global Automotive Production. Review of International Economics 23: 575-605.

Woodford M. 2003. Interest and Prices: Foundations of a Theory of Monetary Policy. Princeton University Press. 


\section{A. PRIOR SPECIFICATION}

To select whether a given regressor should be included or excluded at time $t=0$, we impose a normalgamma (NG) prior akin to Griffin and Brown (2010) on $\boldsymbol{\xi}_{i 0}$, the initial state of $\boldsymbol{\xi}_{i t}$.

$$
\xi_{i 0} \sim \mathcal{N}\left(0_{s_{i}}, \underline{V}_{\xi_{i}}\right)
$$

with $\boldsymbol{0}_{s_{i}}$ a $s_{i}$-dimensional vector of zeros and $\underline{\boldsymbol{V}}_{\xi_{i}}$ is a $k_{i} m_{i} \times k_{i} m_{i}$ diagonal prior variance-covariance matrix. We assume that each diagonal element of $\underline{\boldsymbol{V}}_{\xi_{i}}$, labeled $\underline{\underline{v}}_{\xi_{i}}$, features a Gamma prior with,

$$
\underline{v}_{\xi_{i} j} \sim \mathcal{G}\left(\theta_{i}, \theta_{i} \kappa_{i} / 2\right) \text {. }
$$

The prior has two elements that control the degree of shrinkage, a local parameter and variable specific parameter $\underline{v}_{\xi_{i} j}$ and a global parameter, that pushes all coefficients in a country model towards zero, $\kappa_{i} \sim \mathcal{G}\left(q_{0}, q_{1}\right)$. Also, $\theta_{i}$ denotes a scalar hyperparameter specific to each country that serves to control the tail behavior of the marginal prior. The characteristic of the normal-gamma prior is that even if the global degree of shrinkage is estimated to be very large, the marginal prior (i.e., with $\underline{v}_{\xi_{i} j}$ integrated out) allows for non-zero regression coefficients since it features fat tails. We set $\theta_{i}=0.1$ and $q_{0}=q_{1}=0.01$ (Crespo Cuaresma et al., 2019; Huber et al., 2019).

The degree of time-variation is goverened by the latent threshold approach. Here, we use a Gamma prior on $\vartheta_{i j, 1}^{-1}$

$$
\vartheta_{i j, 1}^{-1} \sim \mathcal{G}\left(n_{0}, n_{1}\right)
$$

For the thresholds, we introduce a prior that is uniformly distributed and depends on $\vartheta_{i j, 1}$,

$$
c_{i j} \mid \vartheta_{i j, 1} \sim \mathcal{U}\left(\pi_{i j, 0} \sqrt{\vartheta}_{i j, 1}, \pi_{i j, 1} \sqrt{\vartheta}_{i j, 1}\right) .
$$

We follow Huber et al. (2019) and set $n_{0}=3$ and $n_{1}=0.03$ and the variance of $\vartheta_{i j, 0}=0.05 \times \hat{\sigma}_{i j}$, with $\hat{\sigma}_{i j}$ denoting the OLS standard deviation of a time-invariant VAR model. We also set $\pi_{i j, 0}=0.1$ and $\pi_{i j, 1}=3$, effectively bounding the thresholds away from zero. This implies that high frequency noise in the latent states is always set equal to zero, effectively reducing uncertainty stemming from this source without seriously distorting inference.

For the log-volatilities, we use the prior setup proposed in Kastner and Frühwirth-Schnatter (2014). This implies that we use a normal prior on $\mu_{i l}\left(l=1, \ldots, k_{i}\right)$ with mean $\underline{\mu}_{i}=0$ and variance $\underline{V}_{\mu_{i}}=100$

$$
\mu_{i l} \sim \mathcal{N}\left(\underline{\mu}_{i}, \underline{V}_{\mu_{i}}\right)
$$

and a beta prior for the persistence parameter $\rho_{i l}$,

$$
\frac{\rho_{i l}+1}{2} \sim \operatorname{Beta}\left(a_{0}, b_{0}\right)
$$

with $a_{0}=2$ and $b_{0}=2$.

Finally, we use a non-conjugate gamma prior for $\varsigma_{i j}^{2},\left(j=1, \ldots, k_{i}\right)$,

$$
\varsigma_{i j}^{2} \sim \mathcal{G}\left(\frac{1}{2}, \frac{1}{2 B_{\varsigma}}\right) \text {. }
$$


This choice does not bound $\varsigma_{i l}^{2}$ away from zero, thus providing more shrinkage than standard typical conjugate inverted gamma priors do. Here, we follow the recommendations provided in Kastner and Frühwirth-Schnatter (2014) and set $B_{\varsigma}=1$.

\section{B. CONVERGENCE PROPERTIES OF THE MCMC ALGORITHM AND RESID- UAL DIAGNOSTICS}

In Fig. B.1 we show several diagnostic checks based on the residuals of the country models, obtained from 10,000 posterior draws after a burn-in phase of 30,000 draws. From the upper left panel we see that the residuals are generally not serially autocorrelated. In the top right panel we show box plots of Z-scores of Geweke's convergence diagnostic (Geweke, 1992) per country. These indicate that the MCMC algorithm has converged to its target distribution since most (absolute) values of the statistic are below the 1.96 threshold. The bottom left panel illustrates the distribution of the trade weights. One assumption underlying the GVAR framework is that the weights are relatively small (see Pesaran et al., 2004). We see that a range of mostly CESEE countries share significant trade links with the euro area (bottom row). For these countries, weights would be more equally distributed if we would analyze not the euro area aggregate but its single countries. However, in the context of monetary policy, this introduces additional challenges since assumptions about how the joint euro area monetary policy is modeled have to be made (see e.g., Georgiadis, 2015; Feldkircher et al., 2019), which is not straightforward in the context of forward guidance. Last, we show in the bottom panel of Fig. B.1, right-hand side that cross-sectional dependence of the country residuals is generally weak. The cumulative density function of the pairwise correlations across the country residuals show that $90 \%$ of the mass lies below $30 \%$ and indicating weak cross-sectional dependence (Burriel and Galesi, 2018).

\section{ADDITIONAL RESULTS}


Fig. B.1: Diagnostics of the estimated GVAR.

(a) Residual serial dependence

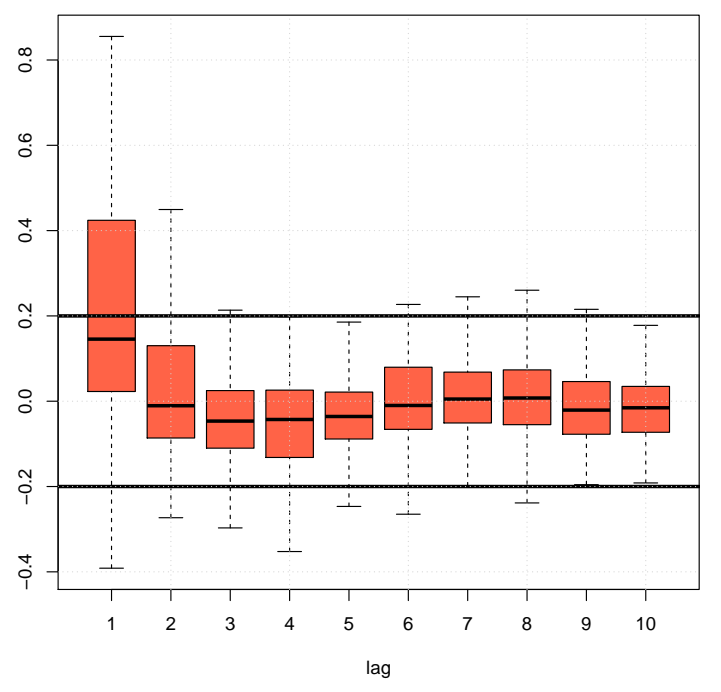

(c) Trade-based weight matrix

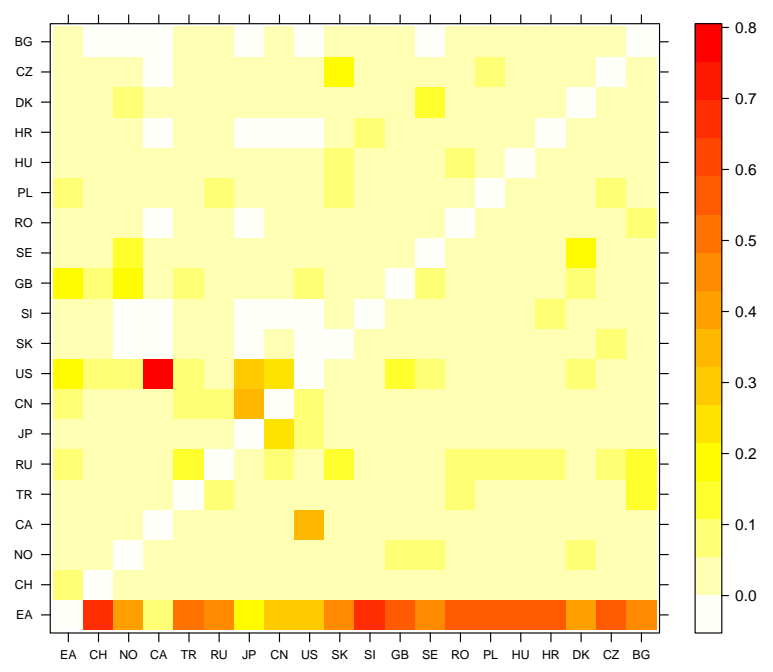

(b) Geweke's convergence diagnostic

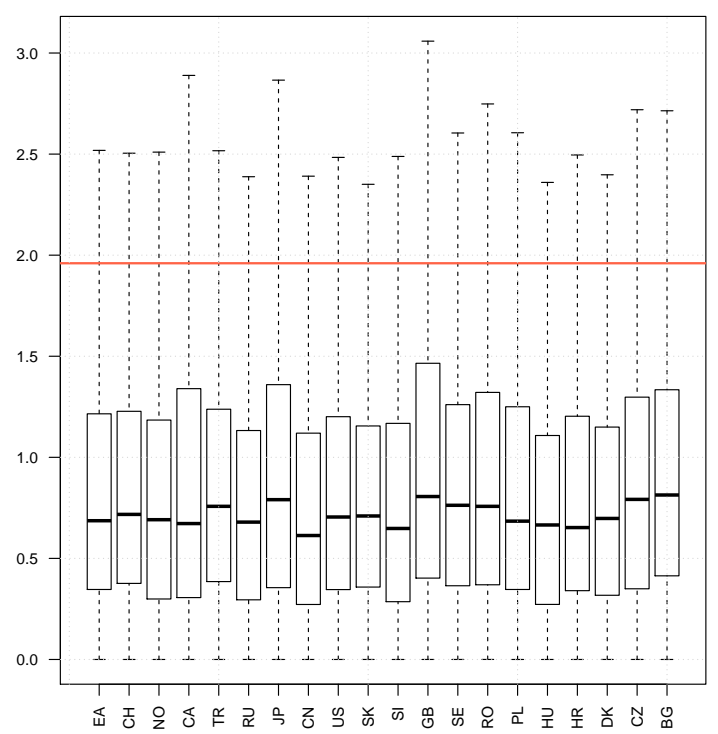

(d) Residual cross-sectional dependence

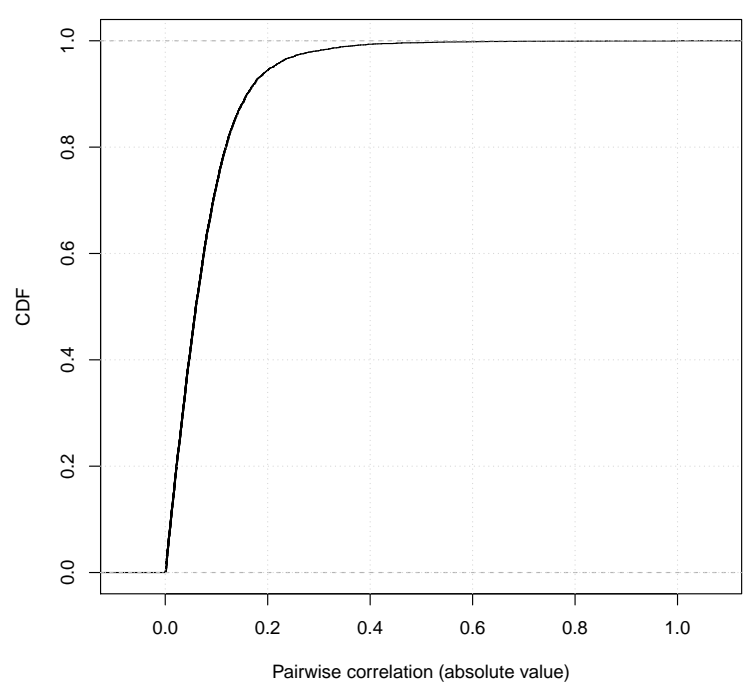

Notes: The top left panel shows the autocorrelation function (ACF) of the cross-country residuals, the right panel boxplots of Z-scores of Geweke's convergence diagnostic (Geweke, 1992). The bottom panel, left hand side shows the distribution of trade weights, the right hand side panel the empirical cumulative density function of average pairwise cross-country residual correlations (in absolute values). 
INTERNATIONAL EFFECTS OF EURO AREA FORWARD GUIDANCE
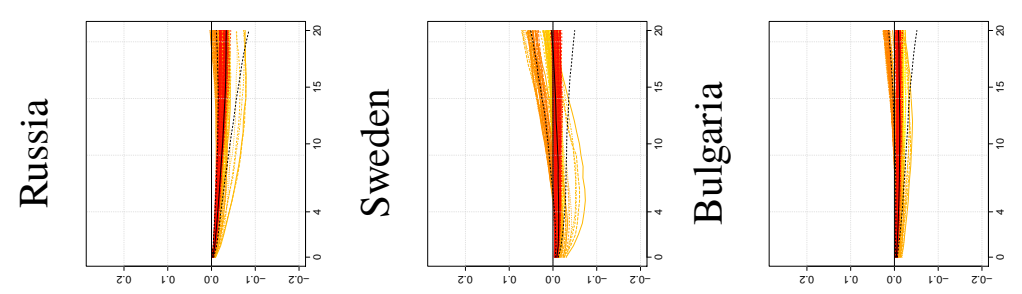

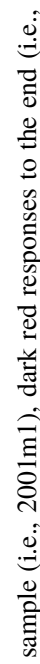
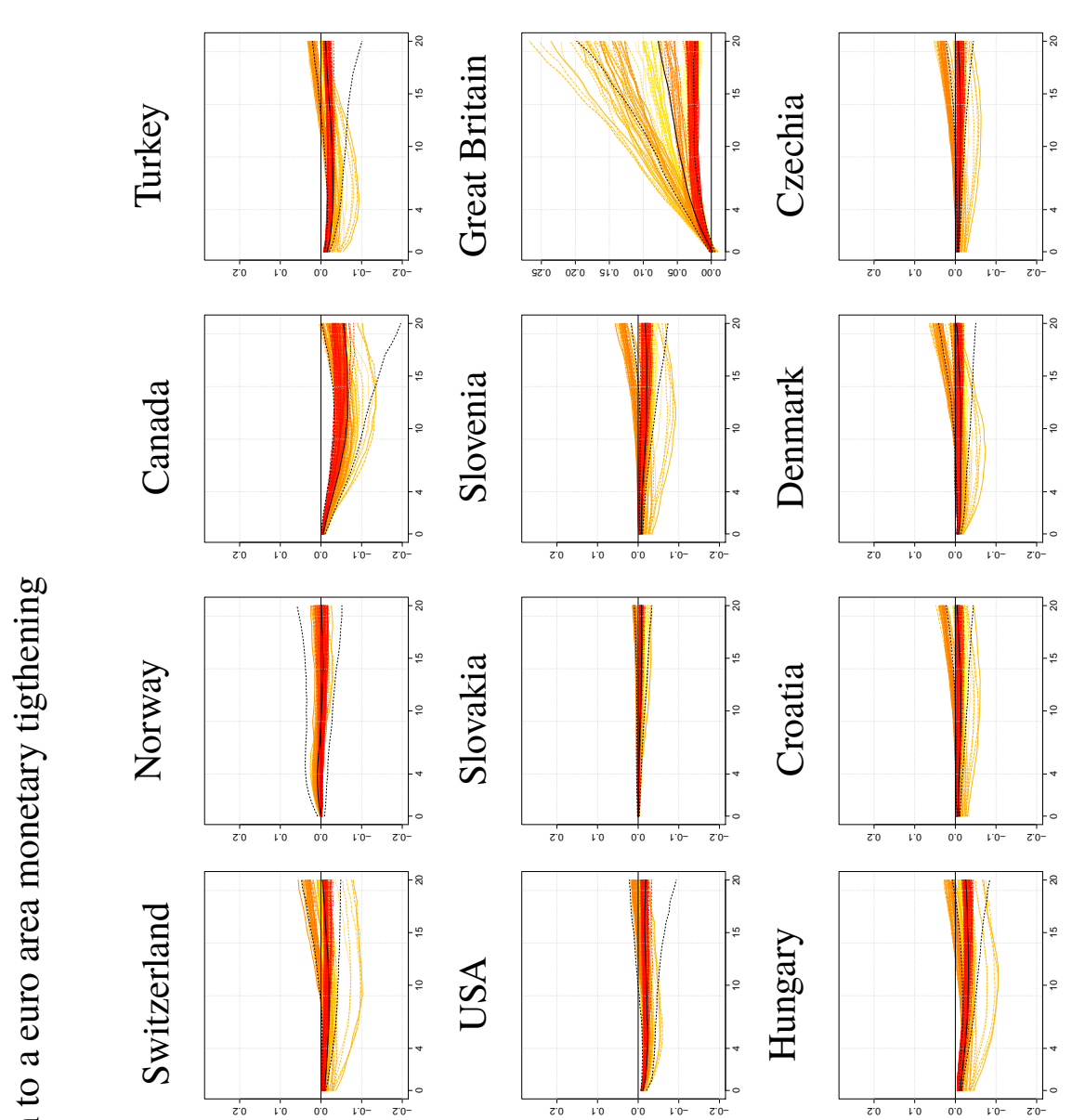

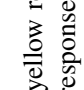
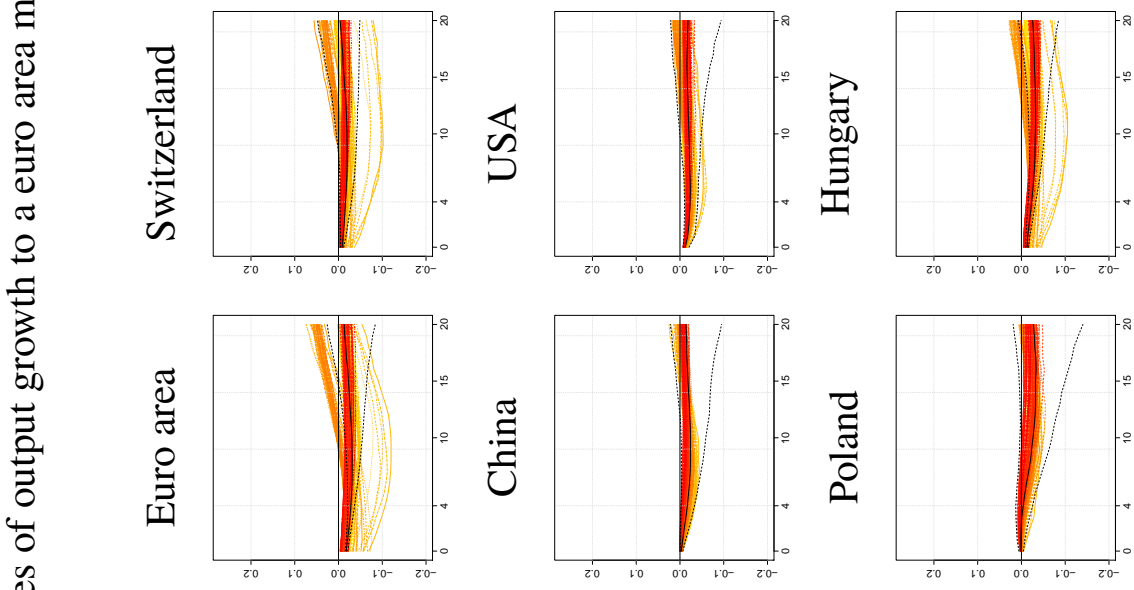

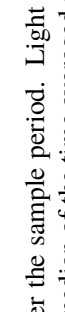

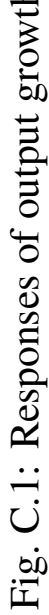
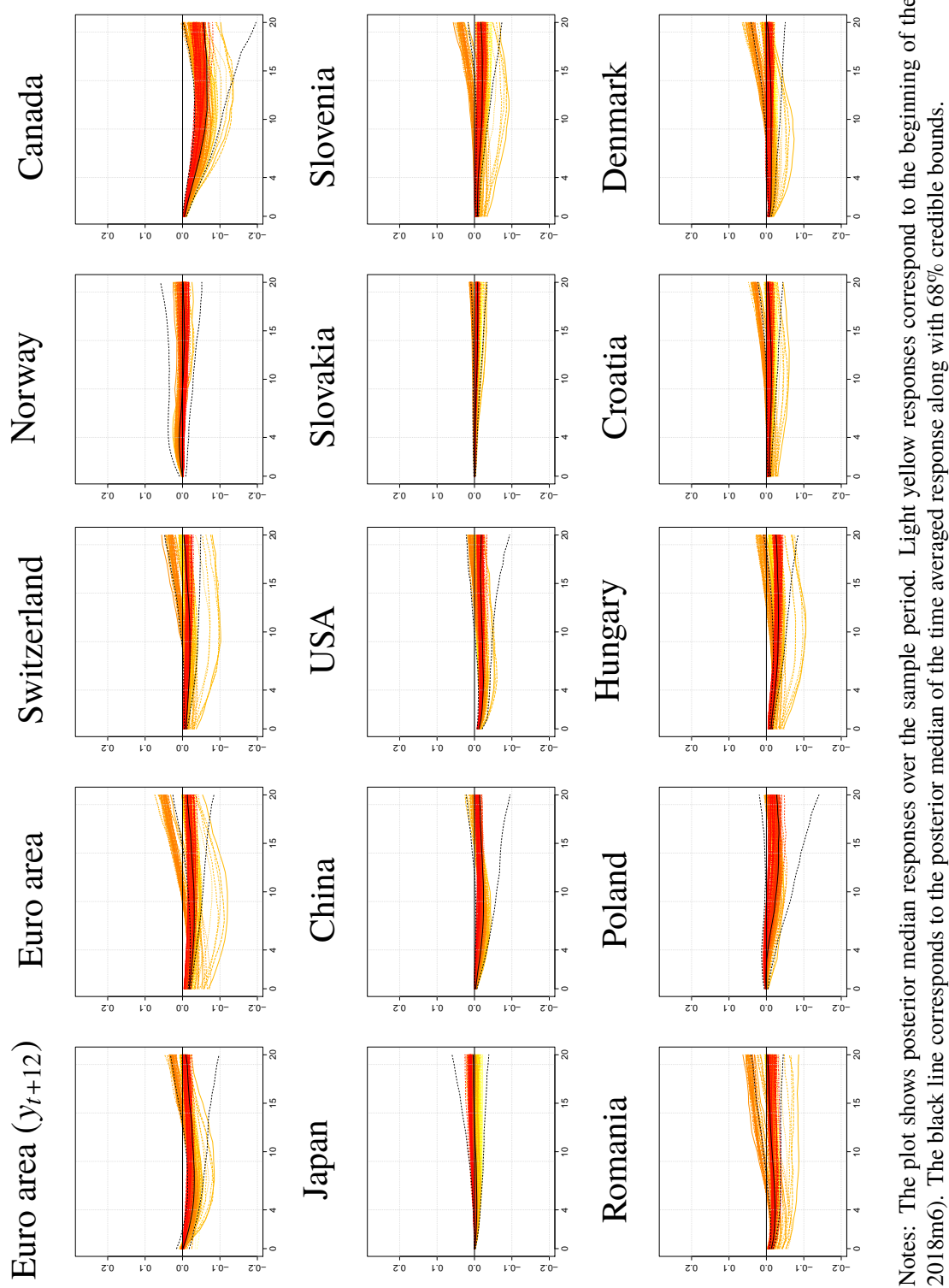





INTERNATIONAL EFFECTS OF EURO AREA FORWARD GUIDANCE
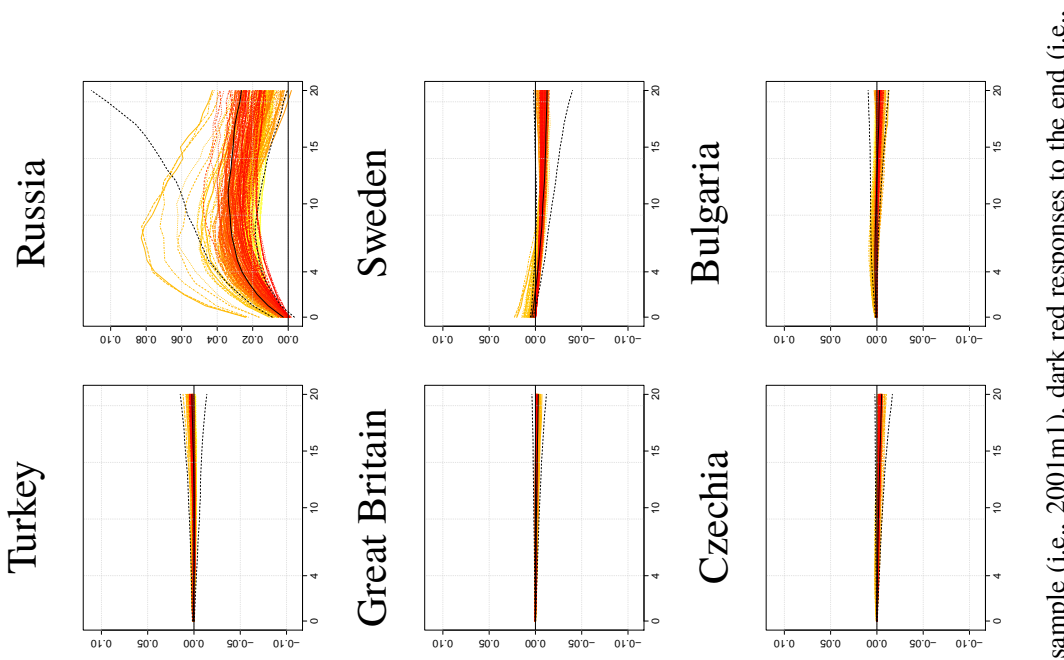

喜

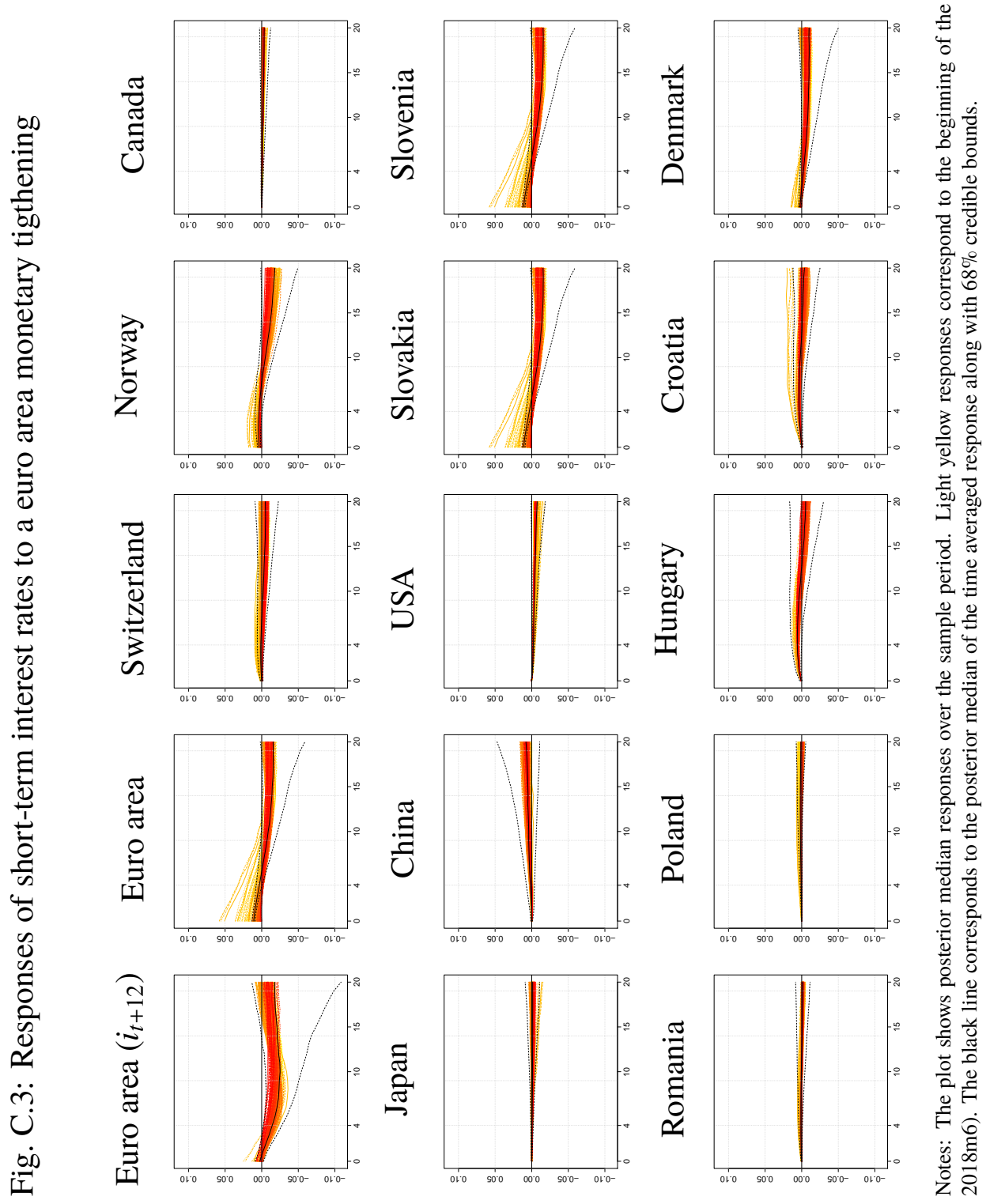




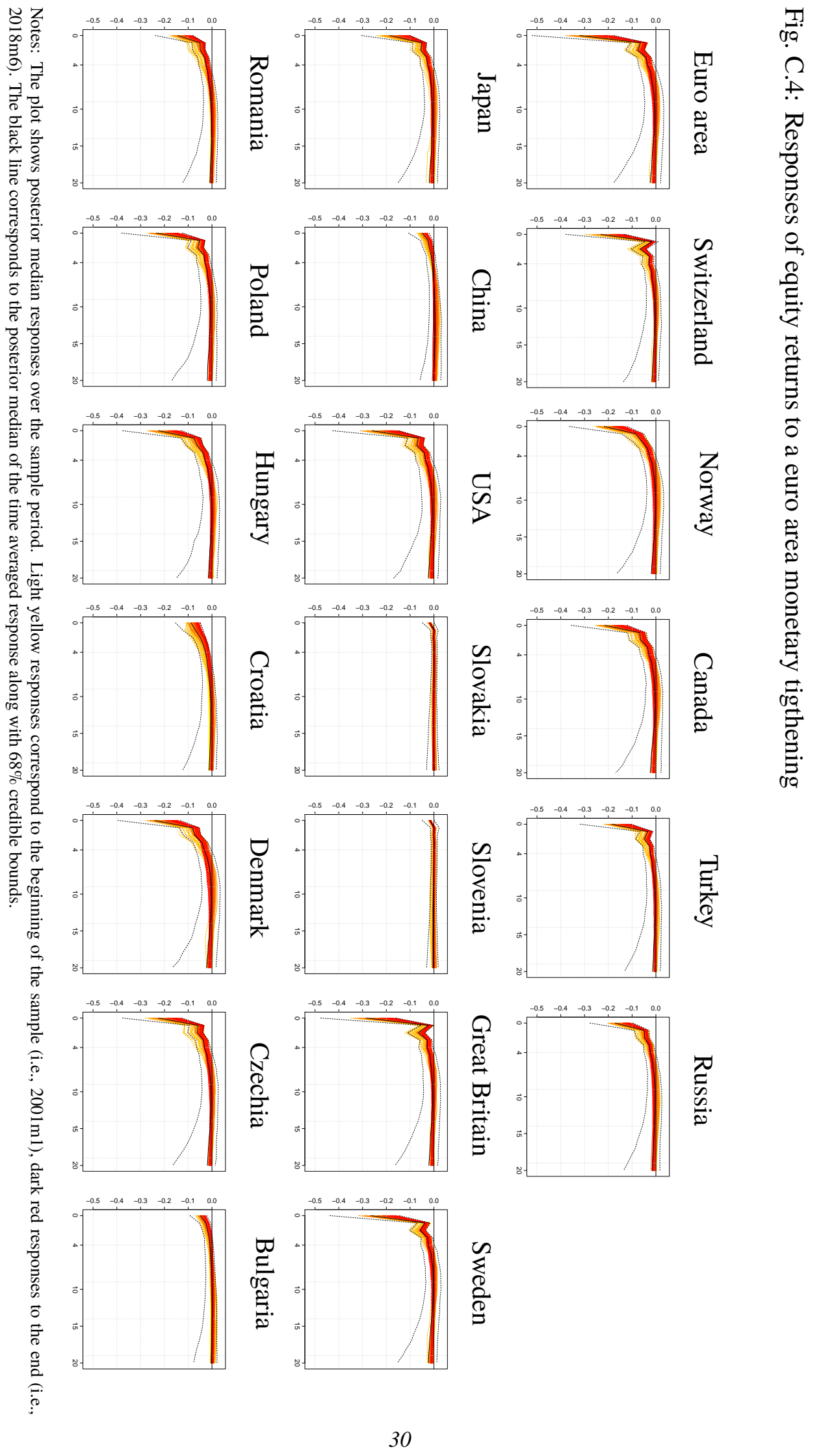


INTERNATIONAL EFFECTS OF EURO AREA FORWARD GUIDANCE
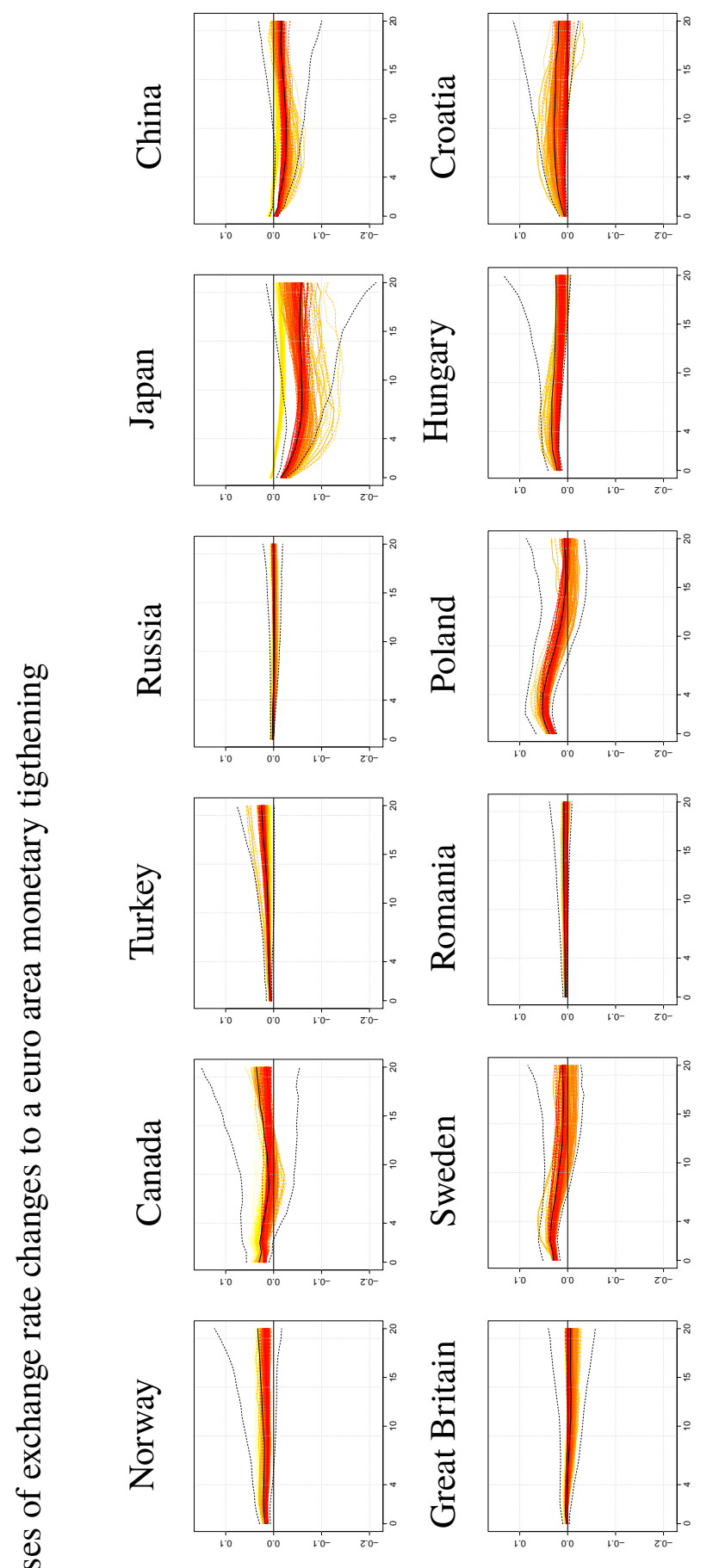

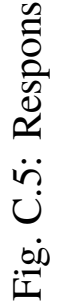
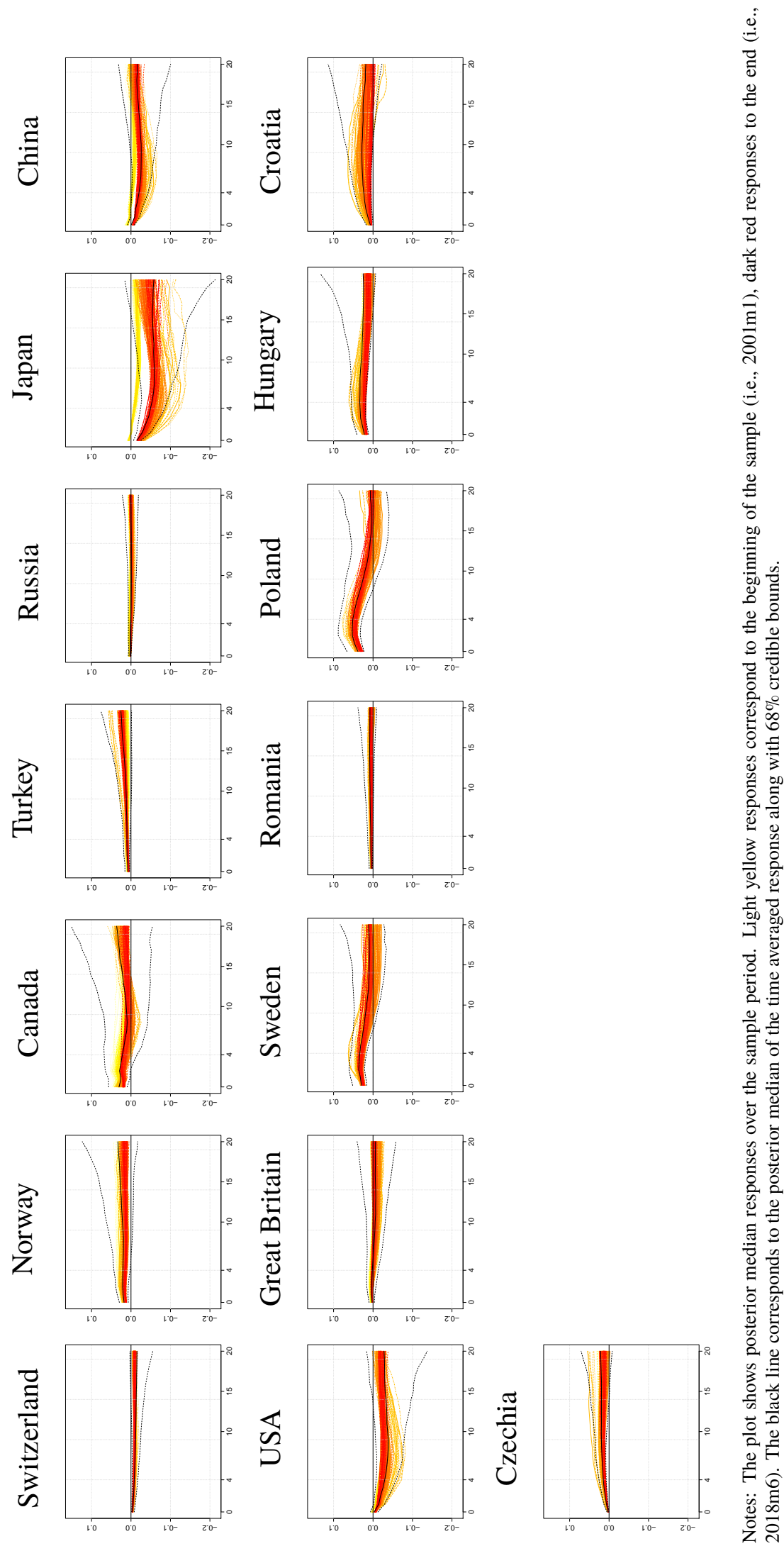

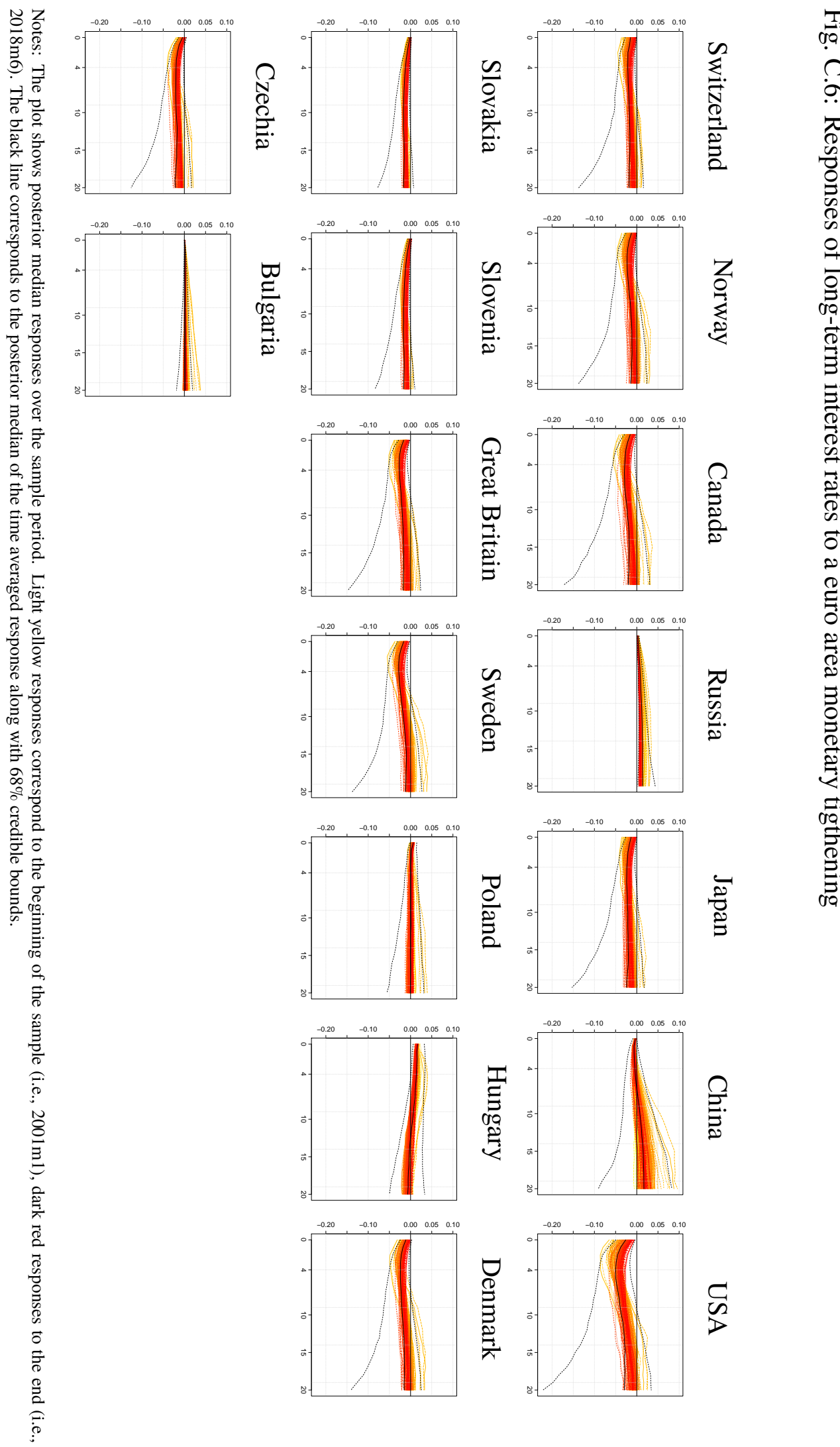

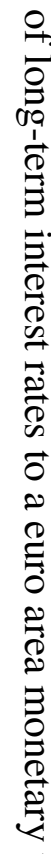
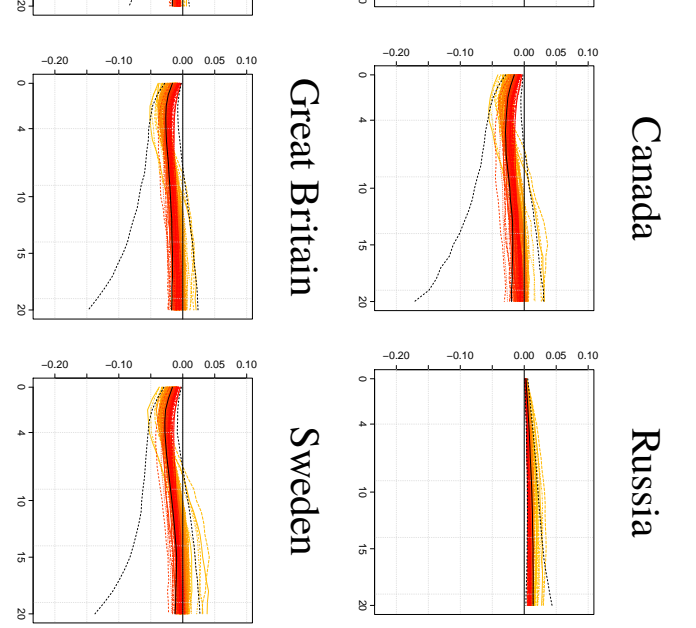

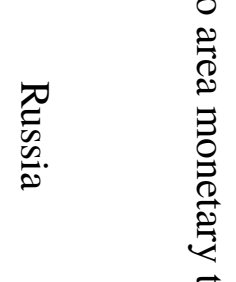
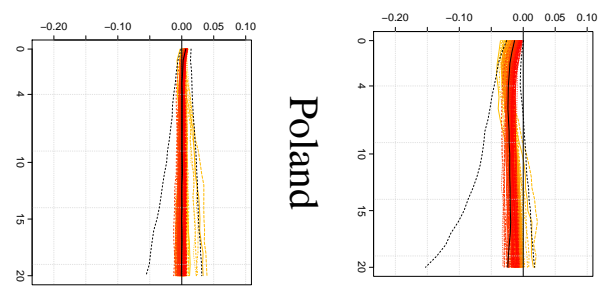

忥
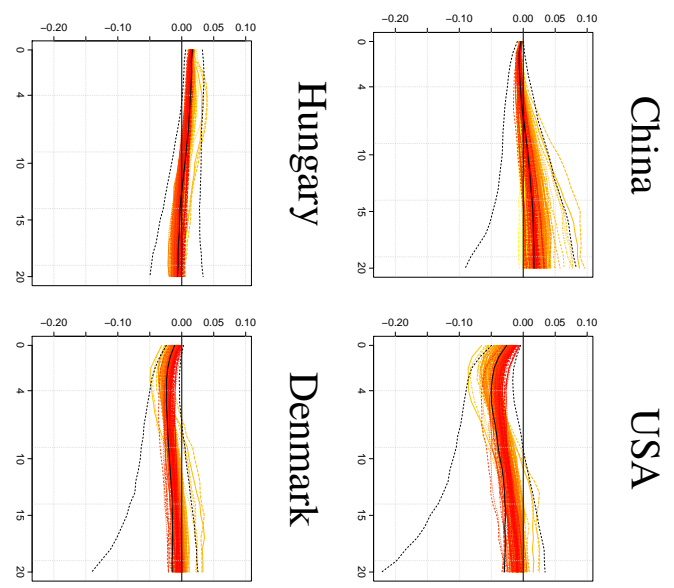
INTERNATIONAL EFFECTS OF EURO AREA FORWARD GUIDANCE
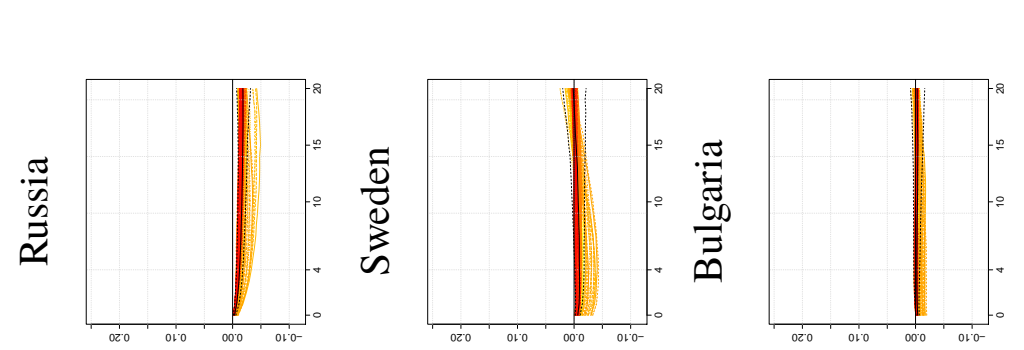

0
0
0
0
9
0
0
0
0
0
0
0
0
0
0
0
0
0
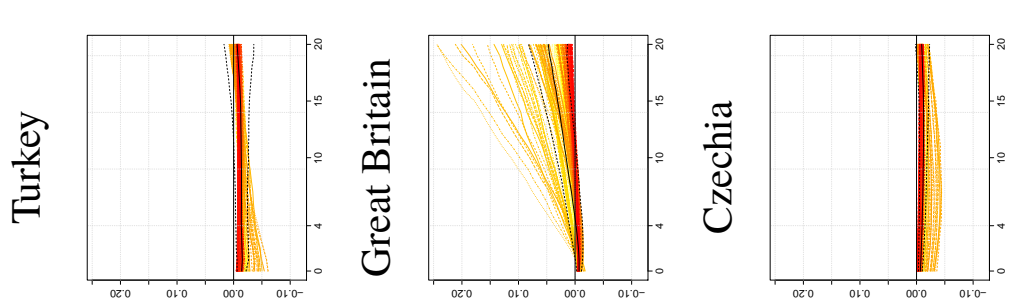

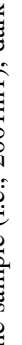

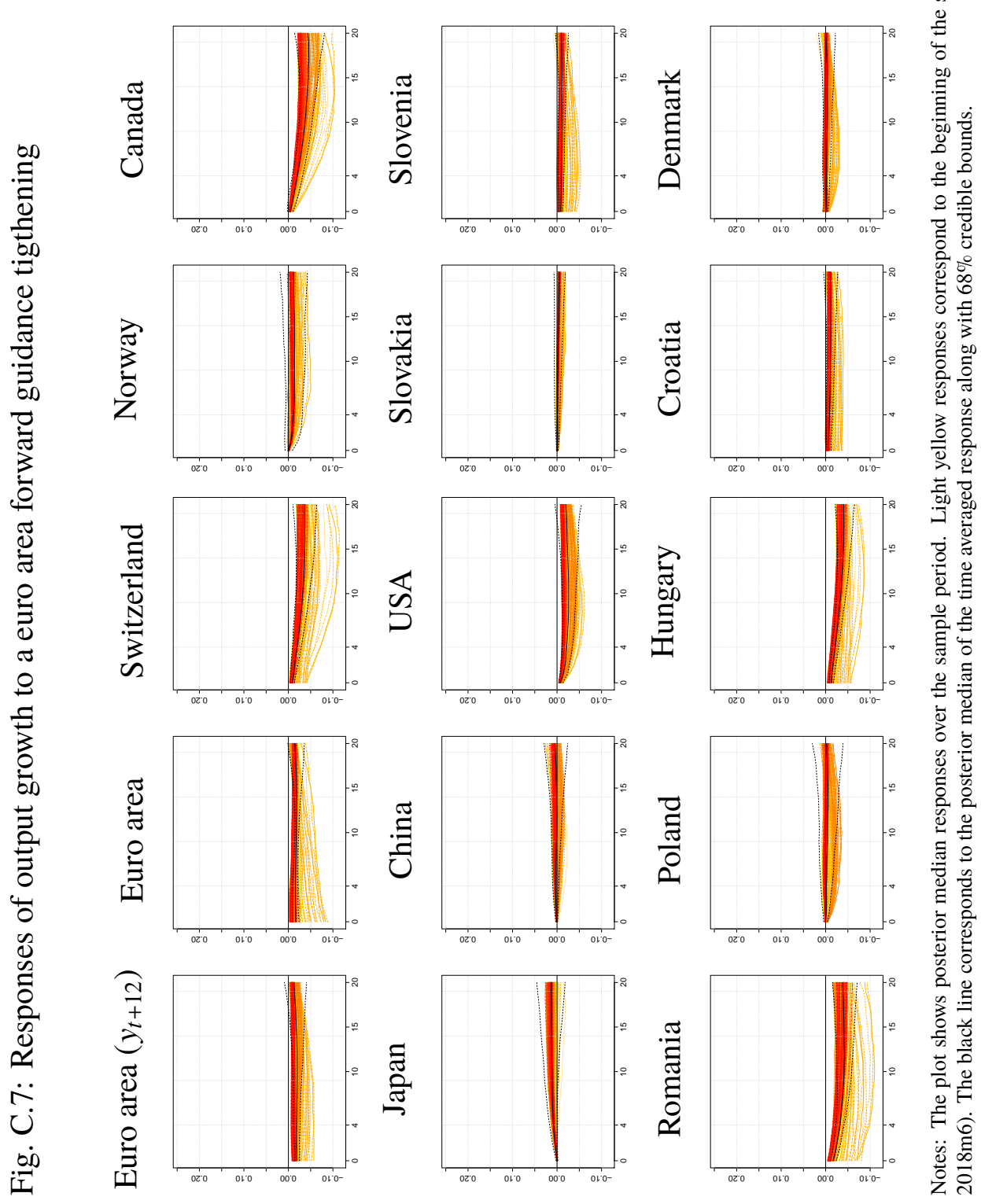




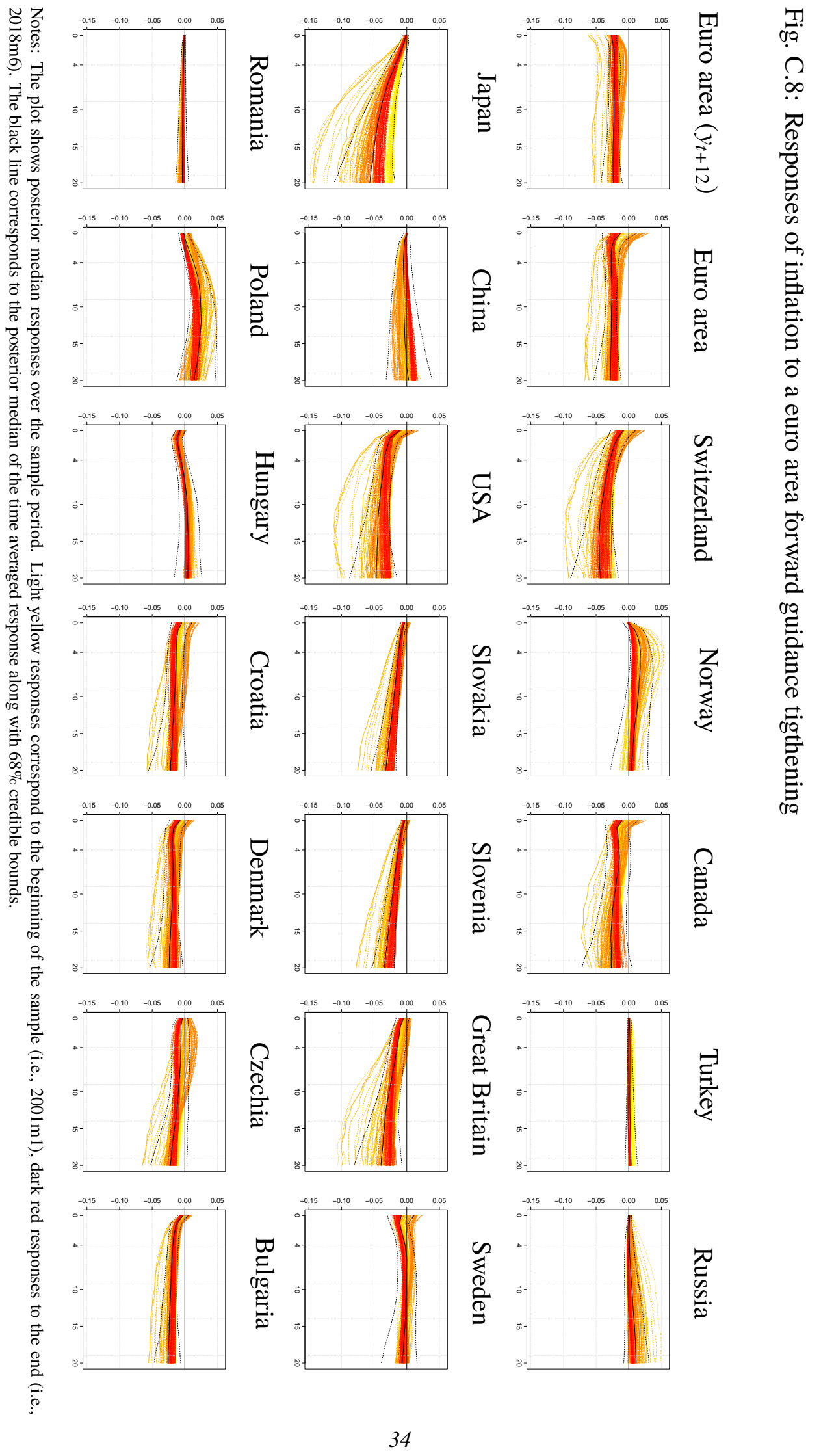


INTERNATIONAL EFFECTS OF EURO AREA FORWARD GUIDANCE
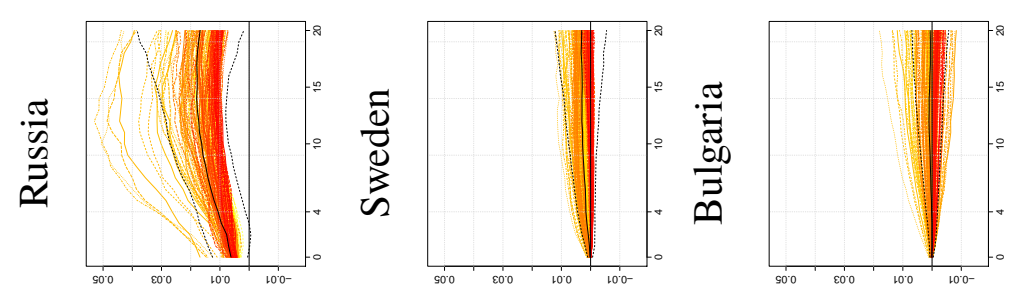

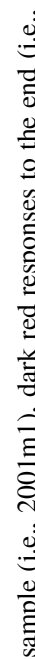
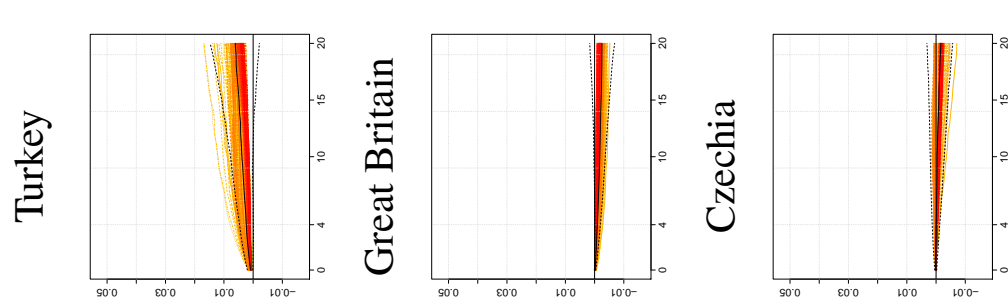

言
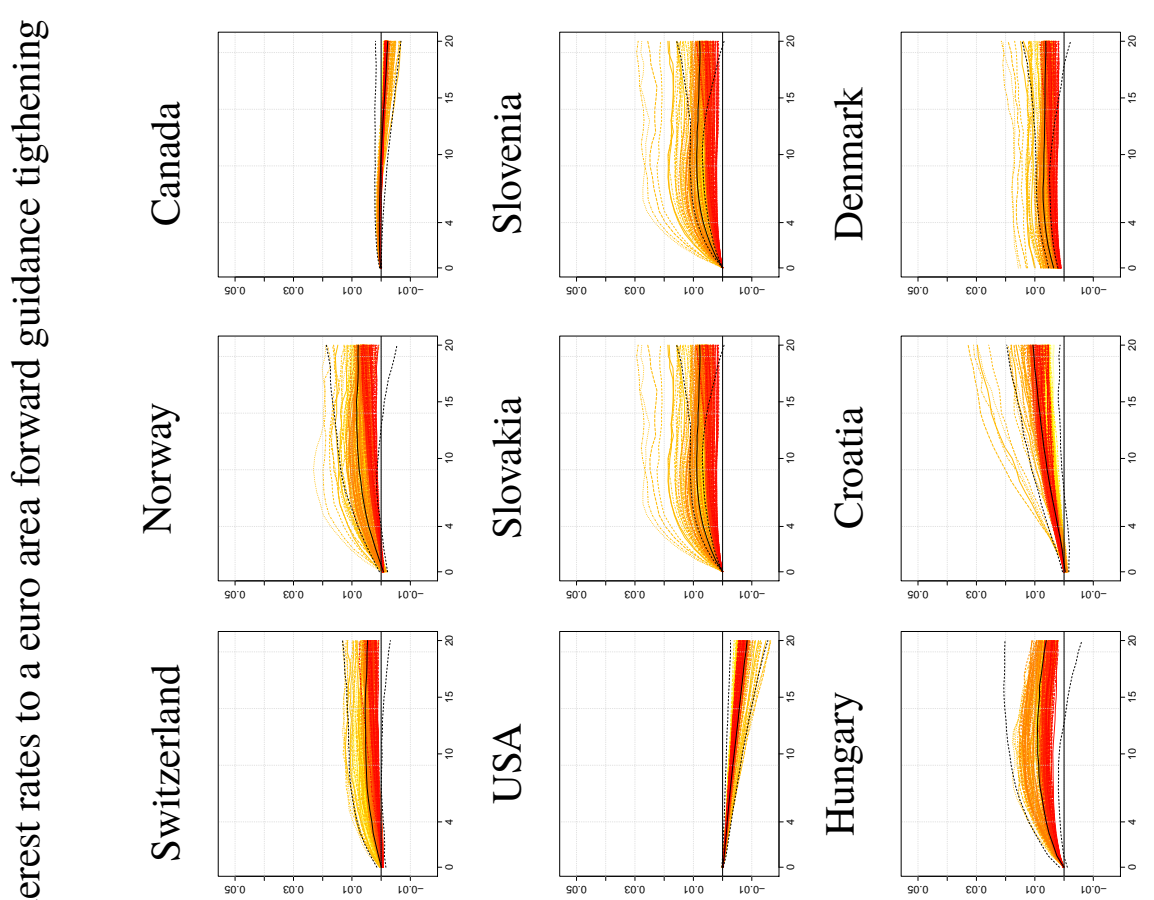

告

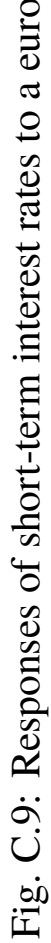
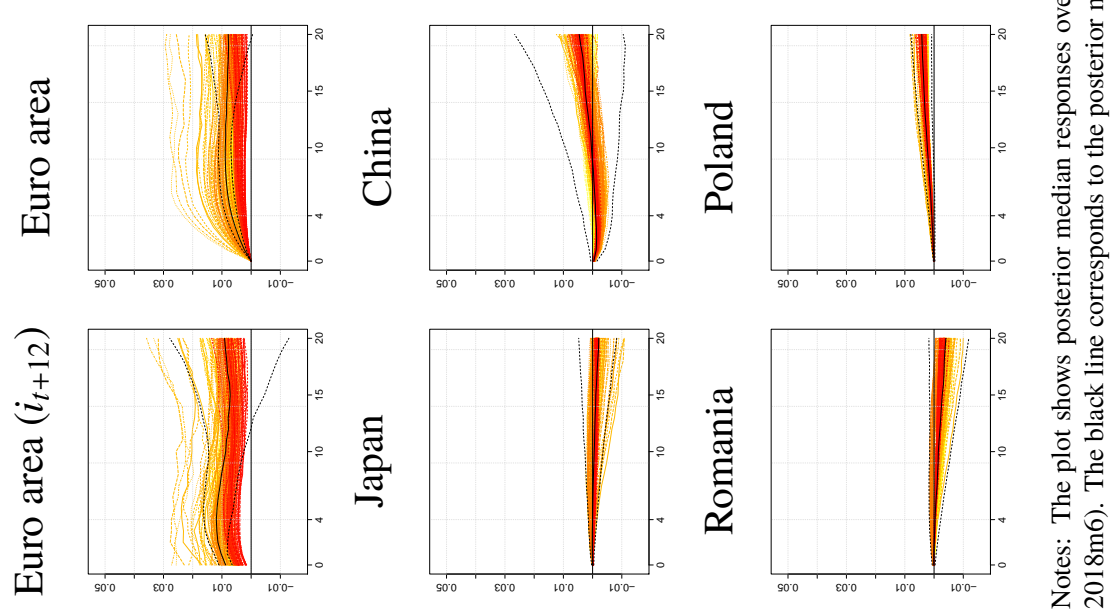


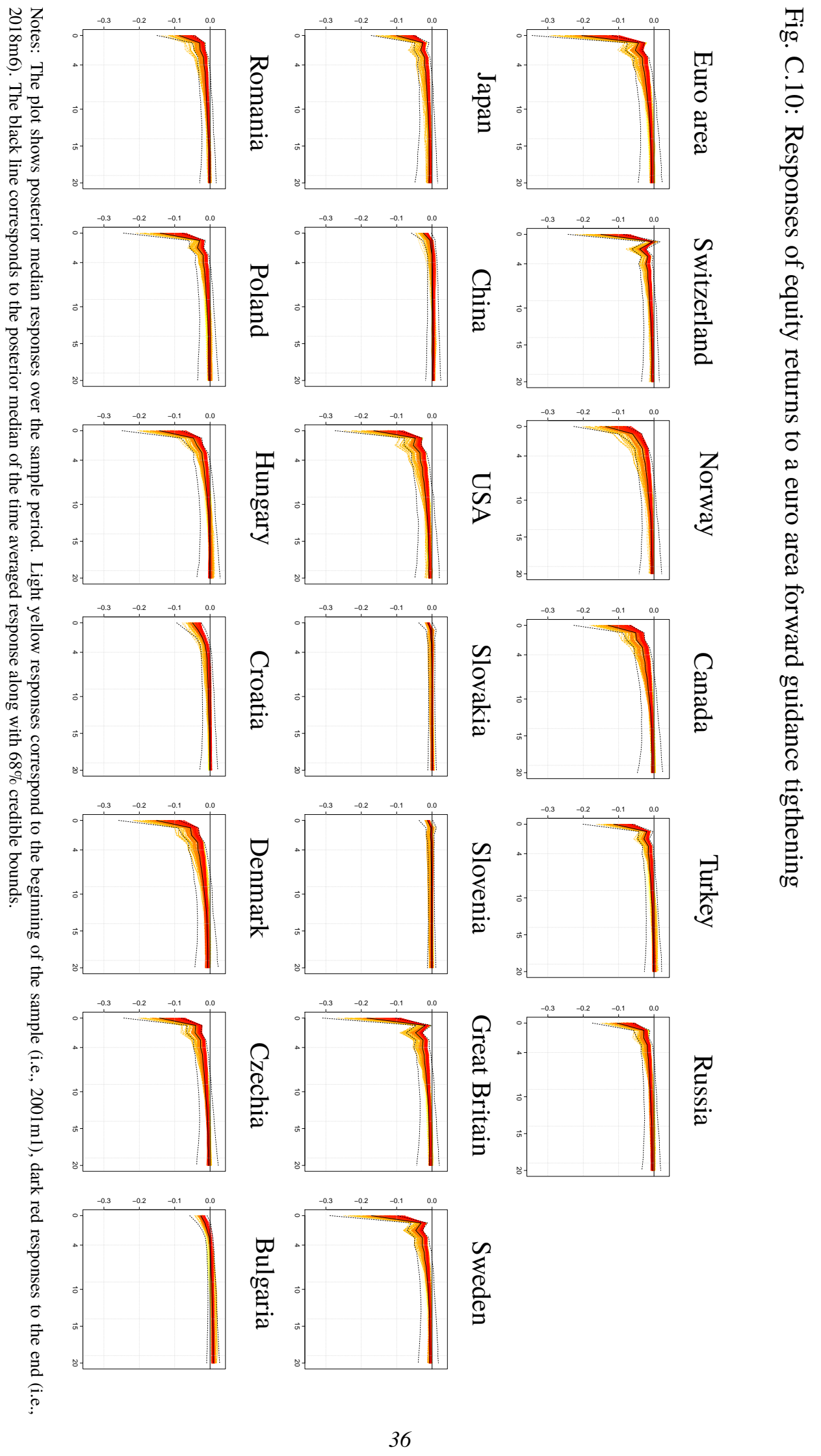


INTERNATIONAL EFFECTS OF EURO AREA FORWARD GUIDANCE
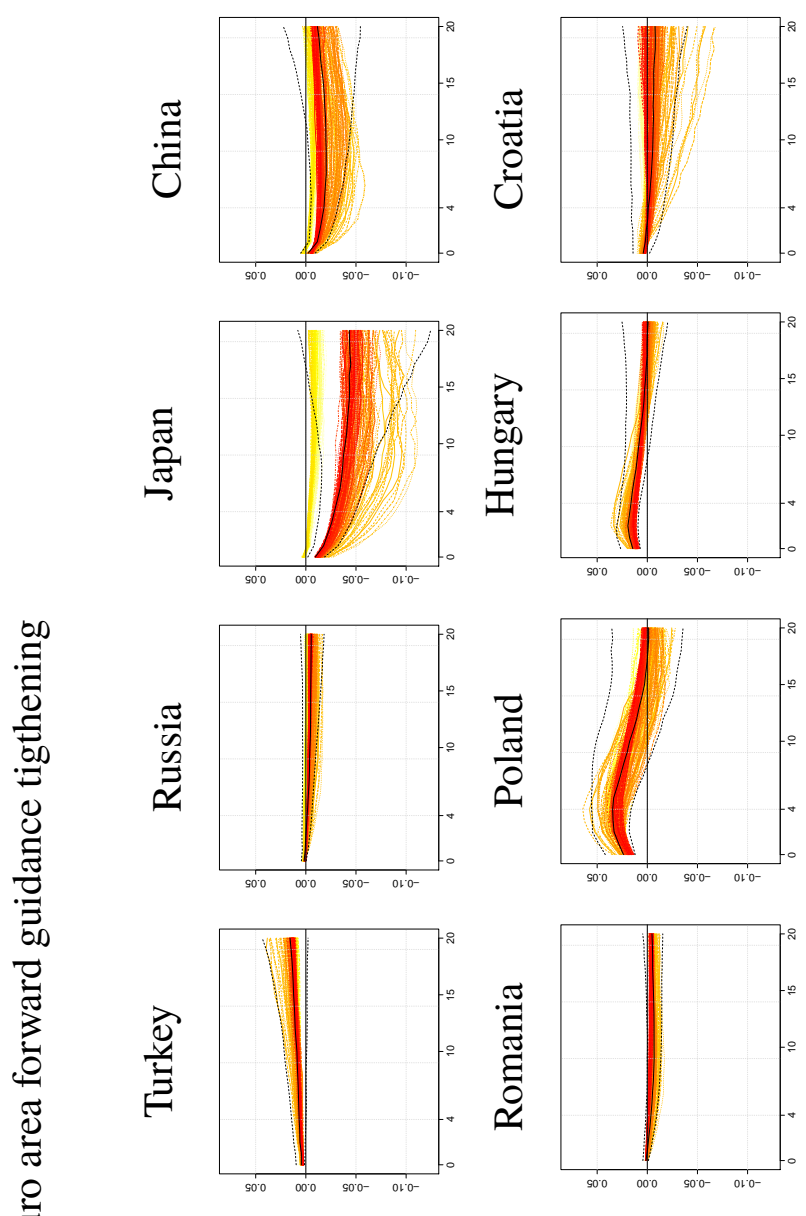

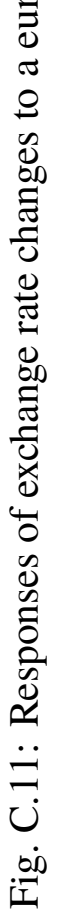
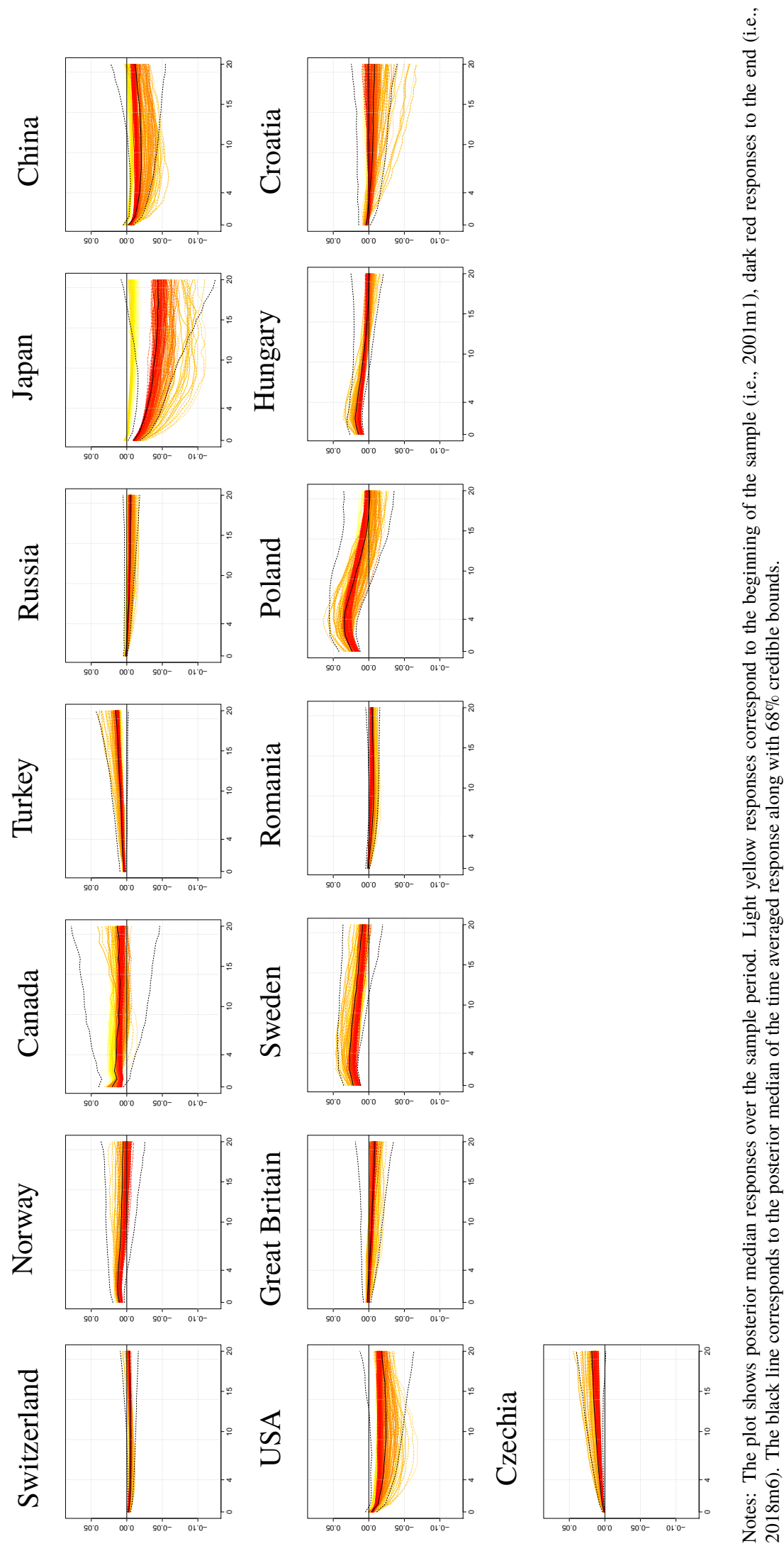

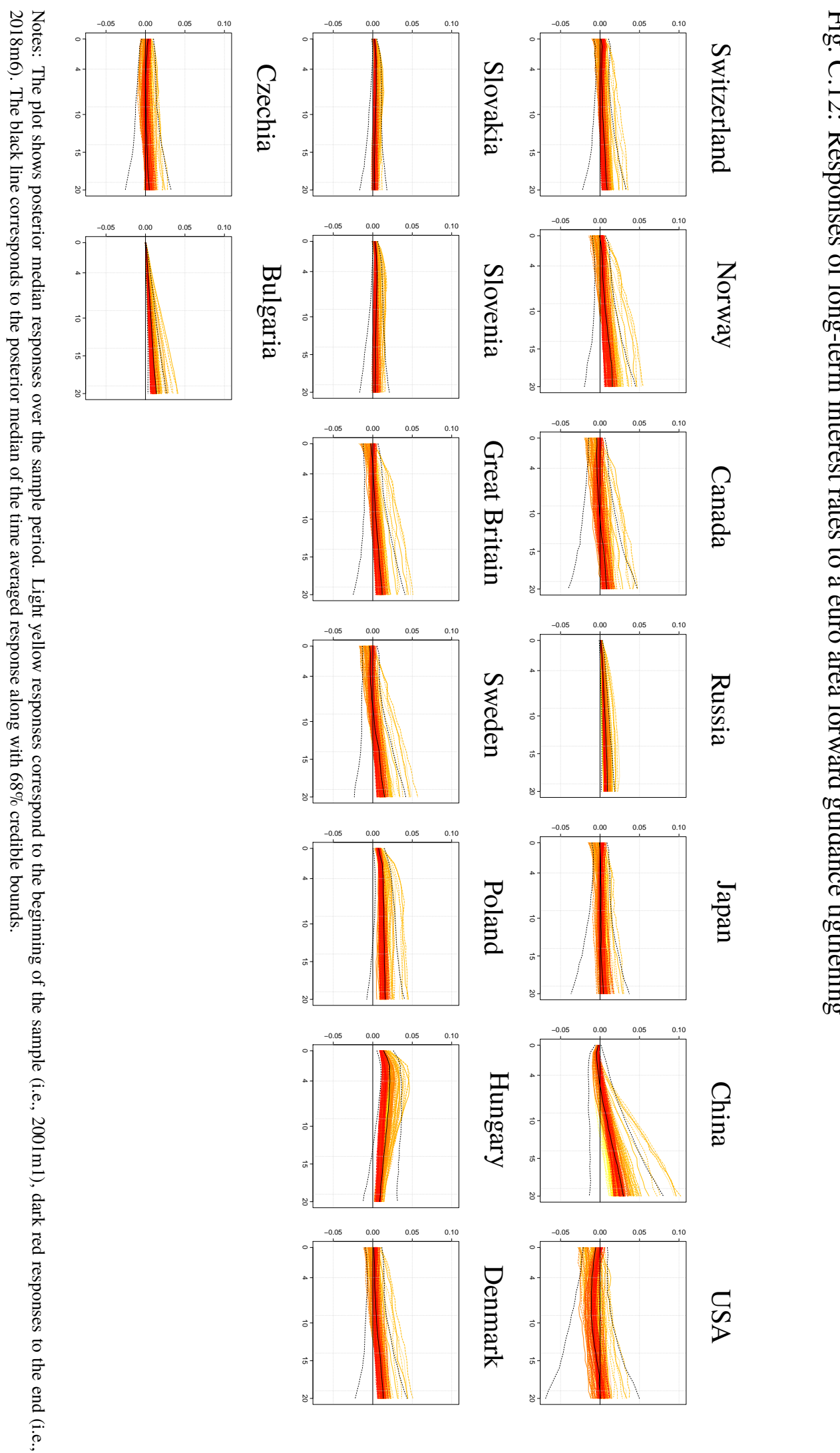

Z్ֶ

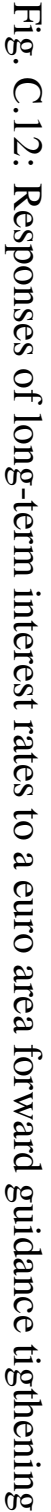
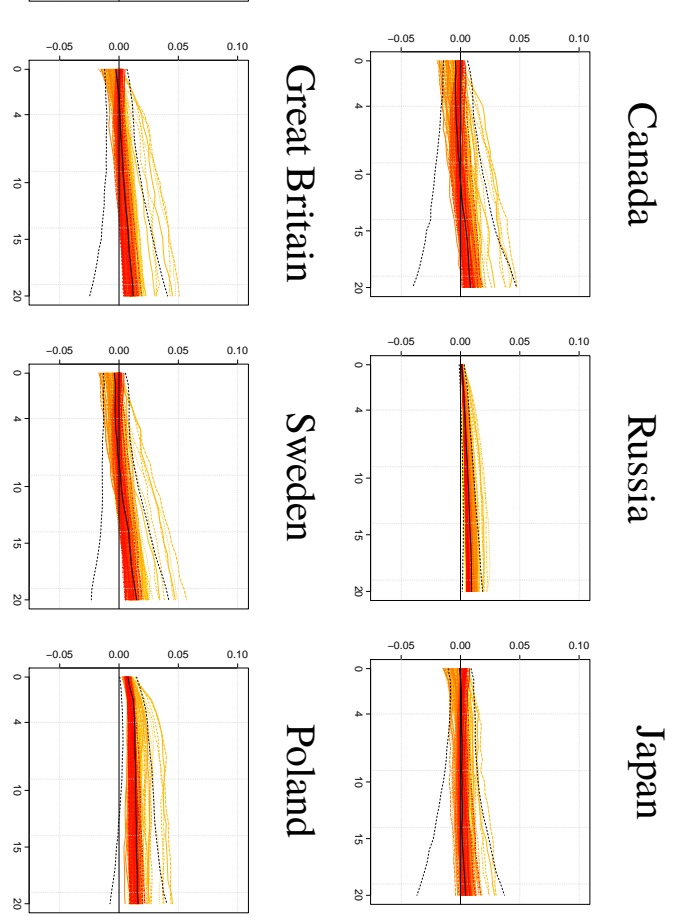

స్ర

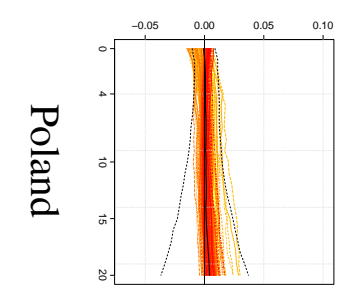

苛
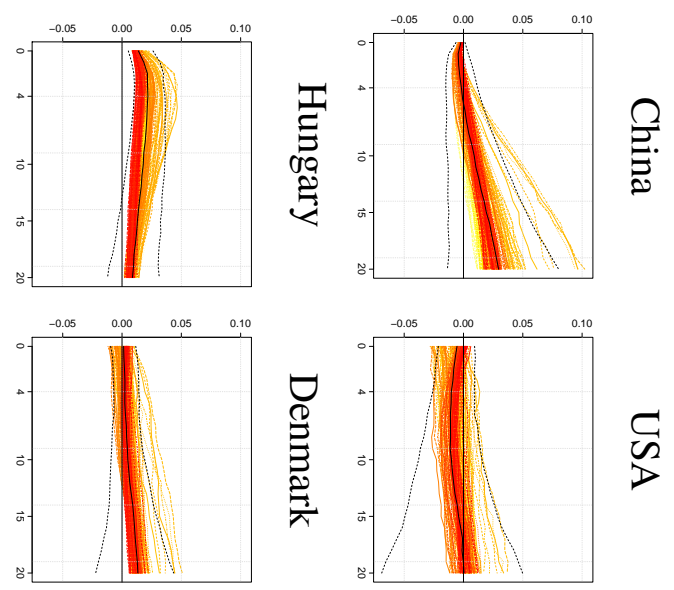
Fig. C.13: Peak effects of time-averaged responses

(a) Output growth

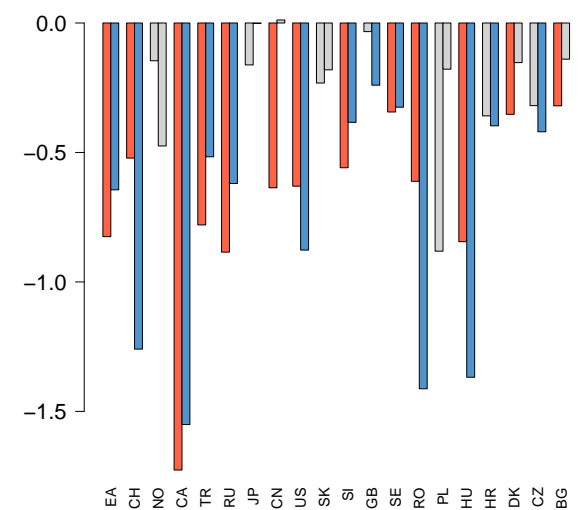

(b) Inflation

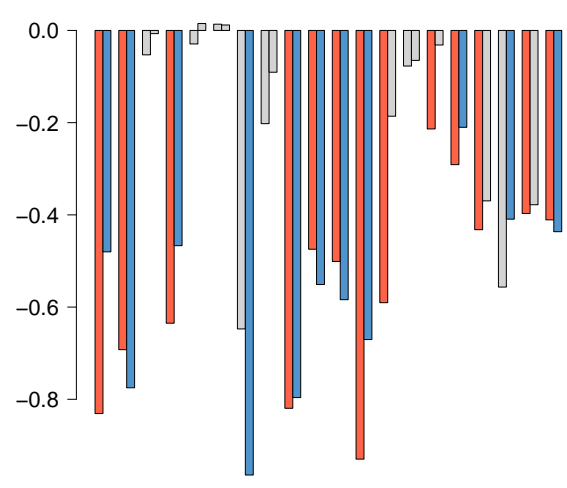

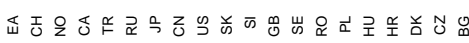

Notes: The figure shows the peak effects of the time-averaged responses. The monetary policy and forward guidance shocks are normalized to $+25 \mathrm{bp}$ on interest rates and interest rate expectations, respectively. Bars in grey indicated non-signficant peak responses according to $68 \%$ credible intervals. 